Article

\title{
Exploring 12‘-Apo- $\beta$-carotenoic-12'-acid as an Ultrafast Polarity Probe for Ionic Liquids
}

Peter W. Lohse, Reinhard Brsing, Thomas Lenzer, and Kawon Oum

J. Phys. Chem. B, 2008, 112 (10), 3048-3057• DOI: 10.1021/jp710766z • Publication Date (Web): 15 February 2008

Downloaded from http://pubs.acs.org on March 24, 2009

\section{More About This Article}

Additional resources and features associated with this article are available within the HTML version:

- Supporting Information

- $\quad$ Links to the 1 articles that cite this article, as of the time of this article download

- $\quad$ Access to high resolution figures

- $\quad$ Links to articles and content related to this article

- $\quad$ Copyright permission to reproduce figures and/or text from this article

\section{View the Full Text HTML}




\title{
Exploring 12'-Apo- $\beta$-carotenoic-12'-acid as an Ultrafast Polarity Probe for Ionic Liquids
}

\author{
Peter W. Lohse, ${ }^{\dagger}$ Reinhard Bürsing, ${ }^{\ddagger}$ Thomas Lenzer, ${ }^{*},+,+$, and Kawon Oum $*, \dagger$ \\ Georg-August-Universität Göttingen, Institut für Physikalische Chemie, Tammannstrasse 6, \\ 37077 Göttingen, Germany and Max-Planck-Institut für biophysikalische Chemie, Abt. Spektroskopie und \\ Photochemische Kinetik (10100), Am Fassberg 11, 37077 Göttingen, Germany
}

Received: November 10, 2007; In Final Form: December 16, 2007

\begin{abstract}
The ultrafast excited-state dynamics of the carbonyl-containing carotenoid $12^{\prime}$-apo- $\beta$-carotenoic- $12^{\prime}$-acid $\left(12^{\prime} \mathrm{CA}\right)$ have been used for probing the microscopic environment in various ionic liquids (ILs). The following IL cations were investigated: 1,3-di- $n$-alkyl-imidazolium featuring different $n$-alkyl chain lengths and also additional methylation at the $\mathrm{C} 2$ position, triethylsulfonium, as well as two tetraalkylammonium ions. These were combined with different anions: $\left[\mathrm{BF}_{4}\right]^{-},\left[\mathrm{PF}_{6}\right]^{-}$, ethyl sulfate $\left(\left[\mathrm{EtOSO}_{3}\right]^{-}\right)$, and bis(trifluoromethylsulfonyl)amide $\left(\left[\mathrm{Tf}_{2} \mathrm{~N}\right]^{-}\right)$. The probe molecule was excited via the $\mathrm{S}_{0} \rightarrow \mathrm{S}_{2}$ transition at 425 or $430 \mathrm{~nm}$, and the characteristic stimulated emission decay of the low-lying excited electronic $\mathrm{S}_{1} / \mathrm{ICT}$ (intramolecular charge transfer) state of $12^{\prime} \mathrm{CA}$ was monitored in the near IR $(850$ or $860 \mathrm{~nm})$. Its lifetime $\tau_{1}$ is sensitive to the micropolarity-induced stabilization of $\mathrm{S}_{1} / \mathrm{ICT}$ relative to $\mathrm{S}_{0}$. The lifetime $\tau_{1}$ of the $\mathrm{S}_{1} / \mathrm{ICT}$ state varies only moderately in all ionic liquids studied here $(\sim 40-110 \mathrm{ps})$, which lies in the range between ethanol (109 ps) and methanol (49 ps). While organic solvents show an excellent correlation of $\tau_{1}$ with the solvent polarity function $\Delta f=(\epsilon-1) /(\epsilon+2)-\left(n^{2}-1\right) /\left(n^{2}+2\right)$, where $\epsilon$ and $n$ are the static dielectric constant and the refractive index of the solvent, respectively, this is not the case for ILs. This is due to dominant local electrostatic probe-cation interactions which cannot be easily quantified by macroscopic quantities. Methylation at the $\mathrm{C} 2$ position of 1,3-di-n-alkyl-imidazolium reduces the accessibility of the cation and therefore the electrostatic stabilization of the probe, resulting in an increase of $\tau_{1}$. A similar increase is observed upon extension of one of the $n$-alkyl chains from ethyl to $n$-decyl. Tetraalkylammonium ILs show an increased $\tau_{1}$ probably due to their more delocalized positive charge which cannot interact so favorably with the probe, in contrast to trialkylsulfonium ILs where the charge is more localized on the sulfur atom. The dependence of $\tau_{1}$ on the IL anion is much weaker, the only notable exception being $\left[\mathrm{EtOSO}_{3}\right]^{-}$, where $12^{\prime} \mathrm{CA}$ experiences a less polar local environment than expected on the basis of extrapolated static dielectric constants. This is possibly due to the competition of the anion and probe for the cation interaction sites. Considerable electrostatic probecation interactions can be also introduced by addition of large amounts of $\mathrm{LiClO}_{4}$ salt to ethanol and diethyl ether. In this case, $\tau_{1}$ also strongly decreases, indicating an efficient coordination of $\mathrm{Li}^{+}$cation(s) with the carbonyl oxygen at the negative end of the probe molecule. The $\mathrm{S}_{1} / \mathrm{ICT} \rightarrow \mathrm{S}_{0}$ internal conversion of the $12^{\prime} \mathrm{CA}$ probe in ILs accelerates with increasing temperature, which can be characterized by an apparent activation energy of a few $\mathrm{kJ} \mathrm{mol}^{-1}$, which is expected for energy-dependent nonradiative processes.
\end{abstract}

\section{Introduction}

An understanding of the solvent structure around a solute and the effect of intermolecular interactions between a solute and the surrounding solvent molecules is a crucial step in the interpretation of the reaction dynamics of solute molecules in liquids. Room-temperature ionic liquids ${ }^{1}$ offer a unique solvent medium consisting exclusively of ions. ${ }^{2-4}$ They are characterized by rather different macroscopic properties compared to organic solvents, such as much higher viscosities and boiling points, indicating highly ordered ion networks in the medium. In ILs compared to organic solvents, a solute molecule experiences quite different degrees of specific Coulomb, dipolar, and hydrogen-bond interactions. One of the advantages of the use of ionic liquids as solvent media is the large number of possible ion combinations, which opens up the possibility of designing

* To whom correspondence should be addressed. Phone: +49 551 3912598. Fax: +49 551 393150. E-mail: koum@gwdg.de.

Georg-August-Universität Göttingen.

$\doteqdot$ Max-Planck-Institut für biophysikalische Chemie. the constituent ions in favor of particular desired solvent-solute/ solvent-solvent interactions.

Ionic liquids have been investigated by various spectroscopic methods either as neat media or in the presence of a probe molecule. For example, the dynamics of neat ionic liquids have been studied via NMR, ${ }^{5,6}$ ESR, ${ }^{7,8}$ optical Kerr effect (OKE), ${ }^{9-14}$ terahertz, ${ }^{15,16}$ neutron scattering, ${ }^{17,18}$ and solvated electron spectroscopy. ${ }^{19-21}$ For an understanding of the solvation dynamics of a probe molecule in ionic liquids after photoexcitation, different incarnations of time-resolved fluorescence spectroscopy have been used, which cover the subpicosecond to nanosecond time scale. ${ }^{22-34}$

A lot of effort has been directed toward characterizing and understanding the static and frequency-dependent dielectric properties of ILs using microwave dielectric spectroscopy in the range from $200 \mathrm{MHz}$ to $20 \mathrm{GHz}$. Extrapolated static dielectric constants $\epsilon$ of most ILs are in the range 9-15, whereas ILs with strongly dipolar anions are characterized by larger dielectric constants, e.g., 27.9 in the case of 1-ethyl-3methylimidazolium ethyl sulfate $\left(\left[\mathrm{C}_{2} \mathrm{mim}\right]^{+}\left[\mathrm{EtOSO}_{3}\right]^{-}\right){ }^{35-40}$ 
One of the IL properties of particular interest in the present work is polarity, which is not a uniquely defined quantity. ${ }^{41}$ From the perspective of dielectric spectroscopy most ILs would be termed as mildly polar on the basis of the macroscopic $\epsilon$ values alone. However, there have been alternative approaches, which use reporter molecules to probe the local environment in the ILs. For instance, extensive studies have been carried out to correlate the absorption/fluorescence band positions of a variety of solvatochromic probes in ILs with the solvent polarity of these media, based on a comparison of the behavior of the same probes in organic solvents. ${ }^{4,41,42}$ Among these, probes such as Reichardt's dye $\left(E_{\mathrm{T}}(30)\right.$ and $E_{\mathrm{T}}{ }^{\mathrm{N}}$ scale $),{ }^{43,44} \mathrm{Nile}-$ Red, pyrene and derivatives, ${ }^{45,46}$-aminophthalimide, ${ }^{47}$ and also water ${ }^{48,49}$ have been used. Many results obtained with such molecules suggest that the "local polarity" of ILs is substantially larger and comparable to that of short-chain alkanols; however, the picture often appears heterogeneous and sometimes contradictory. The correlation between solvatochromic shifts and solvent polarity is not easily defined because it reflects both nonspecific and specific interactions, such as ion-dipole, dipole-dipole, dipole-induced dipole, and hydrogen bonding. Furthermore, correlations from different types of experiments depend obviously on the nature of the reporter molecule, i.e., the relative importance of each individual solute-solvent interaction for that specific probe. This has led to the use of well-known multiparameter polarity scales based on a combination of probes, like the Kamlet-Abboud-Abraham-Taft scale, which tries to establish correlations between the different interaction parameters. ${ }^{41,50,51}$

In this work, we explored $12^{\prime}$-apo- $\beta$-carotenoic- $12^{\prime}$-acid $\left(12^{\prime} \mathrm{CA}\right)$ as an ultrafast probe of the solvent environment in ILs. Particularly appealing is the fact that this probe (in terms of previous findings in organic solvents ${ }^{52}$ ) shows a very pronounced change in lifetime between the midpolar (ca. $230 \mathrm{ps)}$ and highly polar range (ca. $40 \mathrm{ps}$ ), which allows us to distinguish fine details of specific probe-IL intermolecular interactions. As we will show below, the lifetime $\tau_{1}$ of this probe molecule in ILs varies roughly between 40 and $110 \mathrm{ps,} \mathrm{depending} \mathrm{on} \mathrm{the}$ type of ionic liquid. The dynamics of the $12^{\prime} \mathrm{CA}$ molecule therefore reflect local interactions as well as changes in the environment of the probe occurring from the subpicosecond up to the few hundred picosecond regime. The picture that $12^{\prime} \mathrm{CA}$ provides is therefore complementary to "instantaneous" steadystate absorption probes and "slower" fluorescence probes, which are also sensitive to the slow reorganization dynamics of the IL network on longer timescales.

\section{Experimental Section}

The setup for near IR transient absorption/stimulated emission measurements has been previously documented elsewhere. ${ }^{52-55}$ Briefly, a mode-locked Ti:Sa oscillator $(82 \mathrm{MHz})$ produced pulses at 850 or $860 \mathrm{~nm}$ with an average laser power of about $1.0-1.5 \mathrm{~W}$. The intensity-modulated pump beam was generated by directing part of the Ti:Sa fundamental into an acousto-optic modulator (AOM), which operated at a frequency of $2 \mathrm{MHz}$ by means of a pulse generator, and subsequent frequency doubling in an LBO crystal. This resulted in pulse energies $<0.1$ $\mathrm{nJ}$ at a wavelength of 425 or $430 \mathrm{~nm}$. The other part of the fundamental was directly used as probe beam $\left(<1 \mathrm{~nJ}\right.$ pulse $\left.{ }^{-1}\right)$ and time delayed with respect to the pump by a motorized translation stage. The time resolution of the setup was typically about 120 fs. The pump and probe beams (with their relative polarization set to $54.7^{\circ}$ ) were combined in a collinear beamin-beam arrangement and mildly focused into a sample cell,

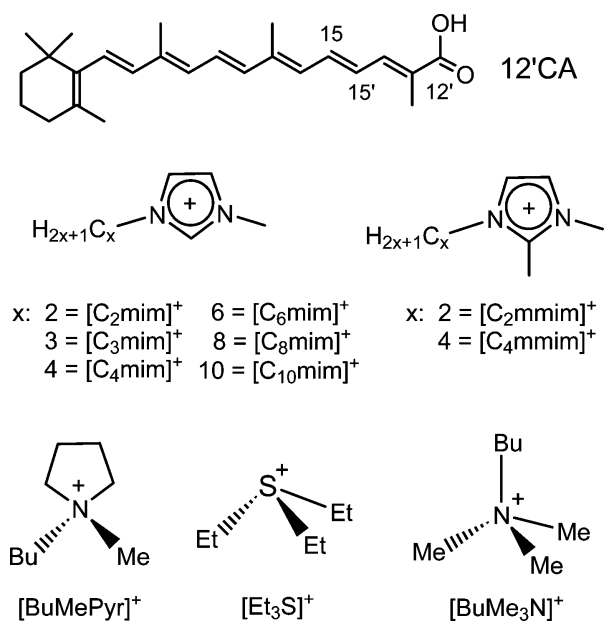

Figure 1. Chemical structures of $12^{\prime}$-apo- $\beta$-carotenoic-12'-acid (top) and cations of the ionic liquids (bottom) used in this paper. Abbreviations: $\left[\mathrm{C}_{2} \mathrm{mim}\right]^{+}=1$-ethyl-3-methylimidazolium, $\left[\mathrm{C}_{3} \mathrm{mim}\right]^{+}=1$ methyl-3-n-propylimidazolium, $\left[\mathrm{C}_{4} \mathrm{mim}\right]^{+}=1-n$-butyl-3-methylimidazolium, $\left[\mathrm{C}_{6} \mathrm{mim}\right]^{+}=1-n$-hexyl-3-methylimidazolium, $\left[\mathrm{C}_{8} \mathrm{mim}\right]^{+}=$ 1-methyl-3-n-octylimidazolium, $\left[\mathrm{C}_{10} \mathrm{mim}\right]^{+}=1$ - $n$-decyl-3-methylimidazolium, $\left[\mathrm{C}_{2} \mathrm{mmim}\right]^{+}=1$-ethyl-2,3-dimethylimidazolium, $\left[\mathrm{C}_{4} \mathrm{mmim}\right]^{+}$ $=1$ - $n$-butyl-2,3-dimethylimidazolium, $[\mathrm{BuMePyr}]^{+}=N$ - $n$-butyl- $N$-methylpyrrolidinium, $\left[\mathrm{Et}_{3} \mathrm{~S}\right]^{+}=$triethylsulfonium, and $\left[\mathrm{BuMe}_{3} \mathrm{~N}\right]^{+}=n$-butyltrimethylammonium.

which has been newly designed for transient absorption measurements in high-viscosity organic solvents and ionic liquids. The stainless steel cell (volume $2 \mathrm{~mL}$ ) used for the present experiments consists of two halves each carrying $1 \mathrm{~mm}$ thick removable quartz windows (Suprasil I). Spacers of different thickness can be inserted between the two halves for varying the path length, which was kept at $2 \mathrm{~mm}$ in the current study. Inside the cell there is an externally driven magnetic stir bar which enables sufficient mixing of viscous solvents. Cooling/ heating coils are embedded in the cell body, which provide accurate temperature control, currently in the range 250-430 $\mathrm{K}$ within $\pm 0.1 \mathrm{~K}$ using a recirculating thermostat. This is especially important for measurements in ILs under well-defined conditions, as their physical properties like viscosity change markedly with temperature. For measurements at low temperatures, the cell is mounted inside a special housing which can be flushed with nitrogen to avoid condensation of moisture.

Chemicals. Highly purified samples of the probe molecule all-trans (all-E)- $12^{\prime}$-apo- $\beta$-carotenoic- $12^{\prime}$-acid (12'CA) were generously provided by BASF AG. All organic solvents had a purity of $99 \%$ or better. $\mathrm{LiClO}_{4}(99.99 \%), \mathrm{LiCl}(99.99 \%)$, and $\mathrm{LiBr}$ $(99.995 \%)$ were all obtained from Aldrich and used as received. The ionic liquids $\left[\mathrm{C}_{4} \mathrm{mim}\right]^{+}\left[\mathrm{BF}_{4}\right]^{-},\left[\mathrm{C}_{2} \mathrm{mim}\right]^{+}\left[\mathrm{EtOSO}_{3}\right]^{-}$, $\left[\mathrm{C}_{2} \mathrm{mim}\right]^{+}\left[\mathrm{N}(\mathrm{CN})_{2}\right]^{-},\left[\mathrm{C}_{2} \mathrm{mmim}\right]^{+}\left[\mathrm{Tf}_{2} \mathrm{~N}\right]^{-}\left(\left[\mathrm{Tf}_{2} \mathrm{~N}\right]^{-}=\right.$bis(trifluoromethylsulfonyl)amide), $\quad\left[\mathrm{C}_{4} \mathrm{mim}\right]^{+}\left[\mathrm{Tf}_{2} \mathrm{~N}\right]^{-}, \quad$ and $\left[\mathrm{C}_{4} \mathrm{mmim}\right]^{+}\left[\mathrm{Tf}_{2} \mathrm{~N}\right]^{-}$were obtained from Solvent Innovation. $\left[\mathrm{C}_{4} \mathrm{mim}\right]^{+}\left[\mathrm{N}(\mathrm{CN})_{2}\right]^{-},\left[\mathrm{C}_{2} \mathrm{mim}\right]^{+}\left[\mathrm{Tf}_{2} \mathrm{~N}\right]^{-},\left[\mathrm{C}_{3} \mathrm{mim}\right]^{+}\left[\mathrm{Tf}_{2} \mathrm{~N}\right]^{-}$, $\left[\mathrm{C}_{6} \mathrm{mim}\right]^{+}\left[\mathrm{Tf}_{2} \mathrm{~N}\right]^{-}, \quad\left[\mathrm{C}_{8} \mathrm{mim}\right]^{+}\left[\mathrm{Tf}_{2} \mathrm{~N}\right]^{-}, \quad\left[\mathrm{C}_{10} \mathrm{mim}\right]^{+}\left[\mathrm{Tf}_{2} \mathrm{~N}\right]^{-}$, $\left[\mathrm{BuMe}_{3} \mathrm{~N}\right]^{+}\left[\mathrm{Tf}_{2} \mathrm{~N}\right]^{-}$, and $[\mathrm{BuMePyr}]^{+}\left[\mathrm{Tf}_{2} \mathrm{~N}\right]^{-}$were provided by IoLiTec and $\left[\mathrm{C}_{4} \mathrm{mim}\right]^{+}\left[\mathrm{PF}_{6}\right]^{-}$and $\left[\mathrm{Et}_{3} \mathrm{~S}\right]^{+}\left[\mathrm{Tf}_{2} \mathrm{~N}\right]^{-}$by Fluka. A list of cation structures and abbreviations can be found in Figure 1. All ILs had specified purities of typically $~ 99 \%$. Special care was exercised to minimize the water content of the ILs. They were all thoroughly dried using molecular sieves (Merck, beads-type, size $0.3 \mathrm{~nm}$ ), which allowed us to arrive at low water contents comparable to those obtainable by standard procedures employing $10^{-3}$ mbar rough vacuum pumping at elevated temperatures. This way, we reached weight percentages of water 
TABLE 1: Internal Conversion $\left(S_{1} / \mathrm{ICT} \rightarrow \mathrm{S}_{0}\right)$ Time Constants $\tau_{1}$ of $12^{\prime}$-Apo- $\beta$-carotenoic-12'-acid in Various Solvents, Steady-State Absorption Maxima, and Some Relevant Physical Properties of the Solvents

\begin{tabular}{|c|c|c|c|c|c|c|c|c|c|c|c|c|c|c|c|}
\hline \multirow[b]{2}{*}{ no. } & \multirow[b]{2}{*}{ solvent } & \multirow[b]{2}{*}{$T(\mathrm{~K})$} & \multicolumn{2}{|l|}{$\eta(\mathrm{cP})^{a}$} & \multirow[b]{2}{*}{$c^{b}$} & \multirow[b]{2}{*}{$\lambda_{\max }^{c}(\mathrm{~nm})$} & \multicolumn{2}{|c|}{$n^{a}$} & \multicolumn{2}{|c|}{$\epsilon^{a}$} & \multirow[b]{2}{*}{$\Delta f^{l}$} & \multicolumn{2}{|c|}{$r_{\text {cation }}(\AA)$} & \multicolumn{2}{|c|}{$\tau_{1}(\mathrm{ps})^{e}$} \\
\hline & & & & ref & & & & ref & & ref & & & ref & & ref \\
\hline 1 & {$\left[\mathrm{C}_{4} \mathrm{mim}^{+}\left[\mathrm{BF}_{4}\right]^{-}\right.$} & 298 & 104 & $f$ & 5.2 & 417 & 1.429 & $l$ & 11.7 & $p$ & 0.523 & 3.60 & $g, p$ & 71 & $o$ \\
\hline 2 & {$\left[\mathrm{C}_{4} \mathrm{mim}^{+}\left[\mathrm{PF}_{6}\right]^{-}\right.$} & 298 & 196 & $f$ & 4.8 & 415 & 1.409 & $m$ & 11.4 & $p$ & 0.529 & 3.60 & $g, p$ & 62 & $o$ \\
\hline 3 & {$\left[\mathrm{C}_{2} \mathrm{mim}\right]^{+}\left[\mathrm{EtOSO}_{3}\right]^{-}$} & 298 & 120 & $f$ & 5.2 & 418 & 1.478 & $n$ & 27.9 & $q$ & 0.617 & 3.34 & $g, p$ & 90 & $o$ \\
\hline 4 & {$\left[\mathrm{C}_{2} \mathrm{mim}\right]^{+}\left[\mathrm{N}(\mathrm{CN})_{2}\right]^{-}$} & 298 & 21 & $f$ & 6.2 & 418 & 1.514 & $o$ & & & & 3.34 & $g, p$ & 43 & $o$ \\
\hline 5 & {$\left[\mathrm{C}_{4} \mathrm{mim}\right]^{+}\left[\mathrm{N}(\mathrm{CN})_{2}\right]^{-}$} & 298 & & & & 417 & 1.509 & $o$ & & & & 3.60 & $g, p$ & 67 & $o$ \\
\hline 6 & {$\left[\mathrm{C}_{2} \mathrm{mim}\right]^{+}\left[\mathrm{Tf}_{2} \mathrm{~N}\right]^{-}$} & 298 & 18 & $f$ & 3.9 & 412 & 1.423 & $l$ & 12.3 & $g, p$ & 0.535 & 3.34 & $g, p$ & 61 & $o$ \\
\hline 7 & {$\left[\mathrm{C}_{2} \mathrm{mmim}\right]^{+}\left[\mathrm{Tf}_{2} \mathrm{~N}\right]^{-}$} & 298 & & & 3.7 & 416 & 1.430 & $l$ & & & & 3.54 & $r$ & 71 & $o$ \\
\hline 8 & {$\left[\mathrm{C}_{3} \mathrm{mim}\right]^{+}\left[\mathrm{Tf}_{2} \mathrm{~N}\right]^{-}$} & 298 & $53(294 \mathrm{~K})$ & $g$ & & 413 & 1.425 & $o$ & 11.8 & $g, p$ & 0.527 & 3.49 & $g, p$ & 67 & $o$ \\
\hline 9 & {$\left[\mathrm{C}_{4} \mathrm{mim}\right]^{+}\left[\mathrm{Tf}_{2} \mathrm{~N}\right]^{-}$} & 298 & 52 & $f$ & 3.4 & 416 & 1.427 & $m$ & 11.6 & $g, p$ & 0.523 & 3.60 & $g, p$ & 65 & $o$ \\
\hline 10 & {$\left[\mathrm{C}_{4} \mathrm{mmim}\right]^{+}\left[\mathrm{Tf}_{2} \mathrm{~N}\right]^{-}$} & 298 & $118(295 \mathrm{~K})$ & $g$ & & 415 & 1.434 & $o$ & 11.5 & $g, p$ & 0.517 & 3.80 & $g, p$ & 96 & $o$ \\
\hline 11 & {$\left[\mathrm{C}_{6} \mathrm{mim}\right]^{+}\left[\mathrm{Tf}_{2} \mathrm{~N}\right]^{-}$} & 298 & 68 & $h$ & 3.1 & 416 & 1.430 & $o$ & & & & 3.86 & $r$ & 97 & $o$ \\
\hline 12 & {$\left[\mathrm{C}_{8} \mathrm{mim}\right]^{+}\left[\mathrm{Tf}_{2} \mathrm{~N}\right]^{-}$} & 298 & 93 & $i$ & 2.8 & 417 & 1.433 & $o$ & & & & 4.12 & $r$ & 111 & $o$ \\
\hline 13 & {$\left[\mathrm{C}_{10} \mathrm{mim}^{+}\left[\mathrm{Tf}_{2} \mathrm{~N}\right]^{-}\right.$} & 298 & & & & 418 & 1.435 & $o$ & & & & 4.38 & $r$ & 101 & $o$ \\
\hline 14 & {$\left[\mathrm{Et}_{3} \mathrm{~S}\right]^{+}\left[\mathrm{Tf}_{2} \mathrm{~N}\right]^{-}$} & 298 & 40 & $j$ & 3.7 & 413 & 1.426 & $o$ & 13.2 & $j$ & 0.546 & 3.48 & $j$ & 64 & $o$ \\
\hline 15 & {$\left[\mathrm{BuMe}_{3} \mathrm{~N}\right]^{+}\left[\mathrm{Tf}_{2} \mathrm{~N}\right]^{-}$} & 298 & $106(294 \mathrm{~K})$ & $j$ & 3.5 & 410 & 1.409 & $o$ & 12.5 & $j$ & 0.546 & 3.61 & $j$ & 85 & $o$ \\
\hline \multirow[t]{6}{*}{16} & {$[\mathrm{BuMePyr}]^{+}\left[\mathrm{Tf}_{2} \mathrm{~N}\right]^{-}$} & 298 & 89 & $f$ & 3.3 & 414 & 1.423 & $o$ & 11.7 & $j$ & 0.534 & 3.75 & $j, p$ & 83 & $o$ \\
\hline & {$[\mathrm{BuMePyr}]^{+}\left[\mathrm{Tf}_{2} \mathrm{~N}\right]^{-}$} & 308 & & & & 414 & 1.421 & $o$ & & & & & & 77 & $o$ \\
\hline & {$[\mathrm{BuMePyr}]^{+}\left[\mathrm{Tf}_{2} \mathrm{~N}\right]^{-}$} & 318 & & & & 413 & 1.418 & $o$ & & & & & & 70 & $o$ \\
\hline & {$[\mathrm{BuMePyr}]^{+}\left[\mathrm{Tf}_{2} \mathrm{~N}\right]^{-}$} & 328 & & & & 412 & 1.415 & $o$ & & & & & & 66 & $o$ \\
\hline & {$[\mathrm{BuMePyr}]^{+}\left[\mathrm{Tf}_{2} \mathrm{~N}\right]^{-}$} & 338 & & & & 411 & 1.412 & $o$ & & & & & & 60 & $o$ \\
\hline & {$[\mathrm{BuMePyr}]^{+}\left[\mathrm{Tf}_{2} \mathrm{~N}\right]^{-}$} & 348 & & & & 410 & 1.409 & $o$ & & & & & & 56 & $o$ \\
\hline 17 & $n$-hexane & 298 & 0.30 & $k$ & 7.6 & 408 & 1.375 & $d$ & 1.9 & $d$ & 0 & & & 233 & $s$ \\
\hline 18 & diethyl ether & 298 & 0.24 & $k$ & 9.5 & 398 & 1.353 & $d$ & 4.3 & $d$ & 0.304 & & & 230 & $s$ \\
\hline 19 & tetrahydrofuran & 298 & 0.46 & $k$ & 12.3 & 407 & 1.407 & $d$ & 7.5 & $d$ & 0.439 & & & 225 & $s$ \\
\hline 20 & $n$-heptanol & 298 & 5.9 & $k$ & 7.1 & 411 & 1.425 & $d$ & 11.8 & $d$ & 0.526 & & & 203 & $s$ \\
\hline 21 & $n$-butanol & 298 & 2.6 & $k$ & 10.9 & 409 & 1.399 & $d$ & 17.8 & $d$ & 0.607 & & & 167 & $s$ \\
\hline 22 & acetone & 298 & 0.31 & $k$ & 13.6 & 407 & 1.356 & $d$ & 21.0 & $d$ & 0.651 & & & 126 & $o$ \\
\hline 23 & ethanol & 298 & 1.1 & $k$ & 17.1 & 407 & 1.361 & $d$ & 25.3 & $d$ & 0.669 & & & 109 & $o$ \\
\hline 24 & methanol & 298 & 0.54 & $k$ & 24.7 & 406 & 1.328 & $d$ & 33.0 & $d$ & 0.711 & & & 49 & $s$ \\
\hline
\end{tabular}

${ }^{a}$ Data at $298 \mathrm{~K}$ unless stated. ${ }^{b}$ Ion concentrations $c$ in $\mathrm{mol} \mathrm{L}^{-1}$ were taken from the "IL Thermo" database (ref 56). ${ }^{c}$ This work. Maximum peak position of the $\mathrm{S}_{0} \rightarrow \mathrm{S}_{2}$ absorption spectrum. ${ }^{d} \Delta f=R(\epsilon)-R(n)$, where $R(\epsilon)=(\epsilon-1) /(\epsilon+2)$ and $R(n)=\left(n^{2}-1\right) /\left(n^{2}+2\right)$ with the dielectric constant $\epsilon$ and the index of refraction $n$ (ref 57). ${ }^{e} \tau_{1}$ values are time constants for the $\mathrm{S}_{1} / \mathrm{ICT} \rightarrow \mathrm{S}_{0}$ transition. ${ }^{f}$ Reference $58 .{ }^{g}$ Reference 36 . ${ }^{h}$ Reference 59. ${ }^{i}$ Reference 60. ${ }^{j}$ Reference 39. ${ }^{k}$ Reference 61. ${ }^{l}$ Reference $4 .{ }^{m}$ Reference 62. ${ }^{n}$ Reference 56. ${ }^{o}$ This work. ${ }^{p}$ Reference $38 .{ }^{q}$ Reference 37. ${ }^{r}$ Cation radii were estimated as described in the text. ${ }^{s}$ Reference 52.

down to 6 ppm, which were routinely checked by Karl Fischer titration. All ILs and IL solutions were stored, prepared, and handled in a glove box under an argon atmosphere. Steadystate absorption spectra were recorded on a Varian Cary $5 \mathrm{E}$ spectrometer.

\section{Results}

Time constants $\tau_{1}$ of the ultrafast internal conversion (IC) process $\mathrm{S}_{1} / \mathrm{ICT} \rightarrow \mathrm{S}_{0}$ of $12^{\prime}$-apo- $\beta$-carotenoic- $12^{\prime}$-acid (12'CA) were determined from the transient absorption/stimulated emission signals. Table 1 summarizes all $\tau_{1}$ values in ionic liquids from this study, which were obtained from a monoexponential fit to the decay of the stimulated emission starting from the 95\% point of each profile, and compares them with those measured previously in organic solvents. ${ }^{52}$ Ionic liquids were selected in a systematic variation of cations and anions. Thermodynamic data of the ILs at $298 \mathrm{~K}$ are also compiled in Table 1 , such as the viscosity $\eta$, ion density (in $\mathrm{mol} \mathrm{L}^{-1}$ ), index of refraction $n$, dielectric constant $\epsilon$, and cation radius $r_{\text {cation. }} \cdot 4,36-39,56-62$

Five different types of anions, $\left[\mathrm{BF}_{4}\right]^{-},\left[\mathrm{PF}_{6}\right]^{-},\left[\mathrm{Tf}_{2} \mathrm{~N}\right]^{-}$, $\left[\mathrm{EtOSO}_{3}\right]^{-}$, and $\left[\mathrm{N}(\mathrm{CN})_{2}\right]^{-}$, were chosen for the cations $\left[\mathrm{C}_{2^{-}}\right.$ $\mathrm{mim}]^{+}$or $\left[\mathrm{C}_{4} \mathrm{mim}\right]^{+}$. In order to explore the effect of $n$-alkyl chain length in $\left[\mathrm{C}_{x} \mathrm{mim}\right]^{+}$-type imidazolium cations, $x$ was varied $\left(2,3,4,6,8\right.$, and 10) while keeping the same $\left[\mathrm{Tf}_{2} \mathrm{~N}\right]^{-}$anion partner. Two sets of ILs with and without methylation at the $\mathrm{C} 2$ position of the imidazolium cation (i.e., $\left[\mathrm{C}_{2} \mathrm{mmim}\right]^{+} /\left[\mathrm{C}_{2^{-}}\right.$ $\mathrm{mim}]^{+}$and $\left[\mathrm{C}_{4} \mathrm{mmim}\right]^{+} /\left[\mathrm{C}_{4} \mathrm{mim}\right]^{+}$) were selected to investigate the influence on $\tau_{1}$ values arising from the increased steric congestion at the imidazolium cation while keeping the same anion partner $\left(\left[\mathrm{Tf}_{2} \mathrm{~N}\right]^{-}\right)$. Another series of cations, $\left[\mathrm{Et}_{3} \mathrm{~S}\right]^{+}$, $\left[\mathrm{BuMe}_{3} \mathrm{~N}\right]^{+}$, and $[\mathrm{BuMePyr}]^{+}$, was selected for a comparison with the imidazolium-type cations to see how the nature of the cation (e.g., aromatic or nonaromatic) influences the experimental $\tau_{1}$ values.

Prior to the measurement of transient absorption/stimulated emission signals of $12^{\prime} \mathrm{CA}$, steady-state absorption spectra were obtained. Figure 2 compares spectra of $12^{\prime} \mathrm{CA}$ in organic solvents and ILs. The absorption band near $\sim 350-500 \mathrm{~nm}$ corresponds to the $\mathrm{S}_{0} \rightarrow \mathrm{S}_{2}$ transition of $12^{\prime} \mathrm{CA}$. The absorption band maxima in various solvents are summarized in Table 1. The spectra in $n$-alkanols in Figure $2 \mathrm{~A}$ show a typical red shift of the absorption maxima as the $n$-alkyl chain length increases from methanol (406 $\mathrm{nm})$ to $n$-heptanol (411 nm). Similar absorption band shapes of the $\left[\mathrm{C}_{4} \mathrm{mim}\right]^{+}$-based ILs were observed when the counteranion was varied as $\left[\mathrm{BF}_{4}\right]^{-},\left[\mathrm{PF}_{6}\right]^{-}$, and $\left[\mathrm{Tf}_{2} \mathrm{~N}\right]^{-}$, with the absorption maxima at 417,415 , and 416 $\mathrm{nm}$, respectively (Table 1 and Figure 2B). One exception was the spectrum of $\left[\mathrm{C}_{4} \mathrm{mim}\right]^{+}\left[\mathrm{N}(\mathrm{CN})_{2}\right]^{-}$where the red edge of the band was less pronounced. When the $n$-alkyl chain length $x$ was increased in $\left[\mathrm{C}_{x} \mathrm{mim}\right]^{+}\left[\mathrm{Tf}_{2} \mathrm{~N}\right]^{-}$-type ILs (for a selection see Figure 2C), the spectra shifted to the red by a rather small amount $(\Delta \lambda=+6 \mathrm{~nm})$ in the series $x=2,3,4,6,8$, and 10, similar to the shift in $n$-alkanols. Spectra of the three nonimidazolium-based ILs, $\left[\mathrm{Et}_{3} \mathrm{~S}\right]^{+}\left[\mathrm{Tf}_{2} \mathrm{~N}\right]^{-},\left[\mathrm{BuMe}_{3} \mathrm{~N}\right]^{+}\left[\mathrm{Tf}_{2} \mathrm{~N}\right]^{-}$, and $[\mathrm{BuMePyr}]^{+}\left[\mathrm{Tf}_{2} \mathrm{~N}\right]^{-}$, are presented in Figure $2 \mathrm{D}$. They are slightly blue shifted but show a band shape similar to that of, e.g., $\left[\mathrm{C}_{4} \mathrm{mim}\right]^{+}\left[\mathrm{Tf}_{2} \mathrm{~N}\right]^{-}$. 


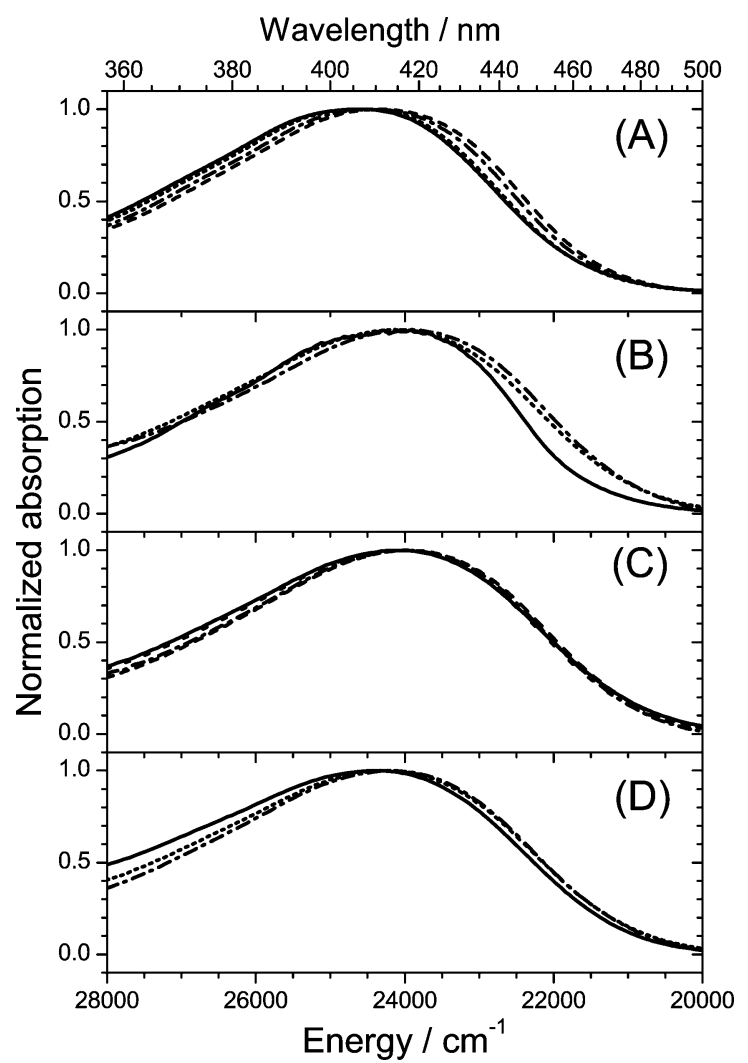

Figure 2. Comparison of steady-state absorption spectra of $12^{\prime}$-apo$\beta$-carotenoic- $12^{\prime}$-acid in organic solvents and various ionic liquids. (A) Polar protic organic solvents: (solid line) methanol, (dotted line) ethanol, (dash-dotted line) $n$-butanol, and (dashed line) $n$-heptanol. (B) $\left[\mathrm{C}_{4} \mathrm{mim}\right]^{+}$- and $\left[\mathrm{C}_{4} \mathrm{mmim}\right]^{+}$-based ILs with different anions: (solid line) $\left[\mathrm{C}_{4} \mathrm{mim}\right]^{+}\left[\mathrm{N}(\mathrm{CN})_{2}\right]^{-}$, (dotted line) $\left[\mathrm{C}_{4} \mathrm{mmim}^{+}\right]\left[\mathrm{Tf}_{2} \mathrm{~N}\right]^{-}$, and (dash-dotted line) $\left[\mathrm{C}_{4} \mathrm{mim}\right]^{+}\left[\mathrm{BF}_{4}\right]^{-}$. (C) $\left[\mathrm{Tf}_{2} \mathrm{~N}\right]^{-}$-based ILs with different cations: (solid line) $\left[\mathrm{C}_{4} \mathrm{mim}\right]^{+}\left[\mathrm{Tf}_{2} \mathrm{~N}\right]^{-}$, (dotted line) $\left[\mathrm{C}_{6} \mathrm{mim}\right]^{+}\left[\mathrm{Tf}_{2} \mathrm{~N}\right]^{-}$, (dashdotted line) $\left[\mathrm{C}_{8} \mathrm{mim}\right]^{+}\left[\mathrm{Tf}_{2} \mathrm{~N}\right]^{-}$, and (dashed line) $\left[\mathrm{C}_{10} \mathrm{mim}\right]^{+}\left[\mathrm{Tf}_{2} \mathrm{~N}\right]^{-}$. (D) Non-imidazolium-based ILs with $\left[\mathrm{Tf}_{2} \mathrm{~N}\right]^{-}$anion: (solid line) $\left[\mathrm{BuMe}_{3} \mathrm{~N}\right]^{+}\left[\mathrm{Tf}_{2} \mathrm{~N}\right]^{-}$, (dotted line) $\left[\mathrm{Et}_{3} \mathrm{~S}\right]^{+}\left[\mathrm{Tf}_{2} \mathrm{~N}\right]^{-}$, and (dash-dotted line) $[\mathrm{BuMePyr}]^{+}\left[\mathrm{Tf}_{2} \mathrm{~N}\right]^{-}$. Absorption signals are normalized to the absorption maxima.

Typical transient absorption/stimulated emission signals of $12^{\prime} \mathrm{CA}$ are presented in Figure 3. 12'CA was excited at $425 \mathrm{~nm}$ (or $430 \mathrm{~nm}$ ) in the $S_{0} \rightarrow S_{2}$ band. The time evolution of the signals was monitored at $850 \mathrm{~nm}$ (or $860 \mathrm{~nm}$ ), where the signal shows an instantaneous rise and ultrafast decay at early time (corresponding to the formation and decay of the short-lived $\mathrm{S}_{2} \rightarrow \mathrm{S}_{n}$ absorption band), followed by a strong stimulated emission from the longer lived $\mathrm{S}_{1} / \mathrm{ICT}$ state. This signal shape is characteristic for a number of apocarotenoids with terminal carbonyl substitution. ${ }^{52,63,64}$ The stimulated emission signal decays toward zero, from which $\tau_{1}$ values were determined by monoexponential fits (see Figure 4 and Table 1). As one specific example, Figure 3 compares the decay of the stimulated emission in the $\left[\mathrm{C}_{x} \mathrm{mim}\right]^{+}\left[\mathrm{Tf}_{2} \mathrm{~N}\right]^{-}$series with $x=2,3,6$, and 8 . The decay becomes slower with increasing $n$-alkyl chain length. It should be noted that the dependence of $\tau_{1}$ values on the increase of $n$-alkyl chain length is much weaker in $\left[\mathrm{C}_{x} \mathrm{mim}\right]^{+}$ $\left[\mathrm{Tf}_{2} \mathrm{~N}\right]^{-}$-type ILs, compared to that previously observed in $n$-alkanols: A direct comparison is shown in the inset of Figure 3.

We also investigated the temperature dependence of $\tau_{1}$ for $12^{\prime} \mathrm{CA}$ over the range $298-348 \mathrm{~K}$ in $[\mathrm{BuMePyr}]^{+}\left[\mathrm{Tf}_{2} \mathrm{~N}\right]^{-}$. The $\mathrm{S}_{1} / \mathrm{ICT} \rightarrow \mathrm{S}_{0}$ internal conversion process became faster at higher temperatures. Experimental $\tau_{1}(T)$ values and the temperature-

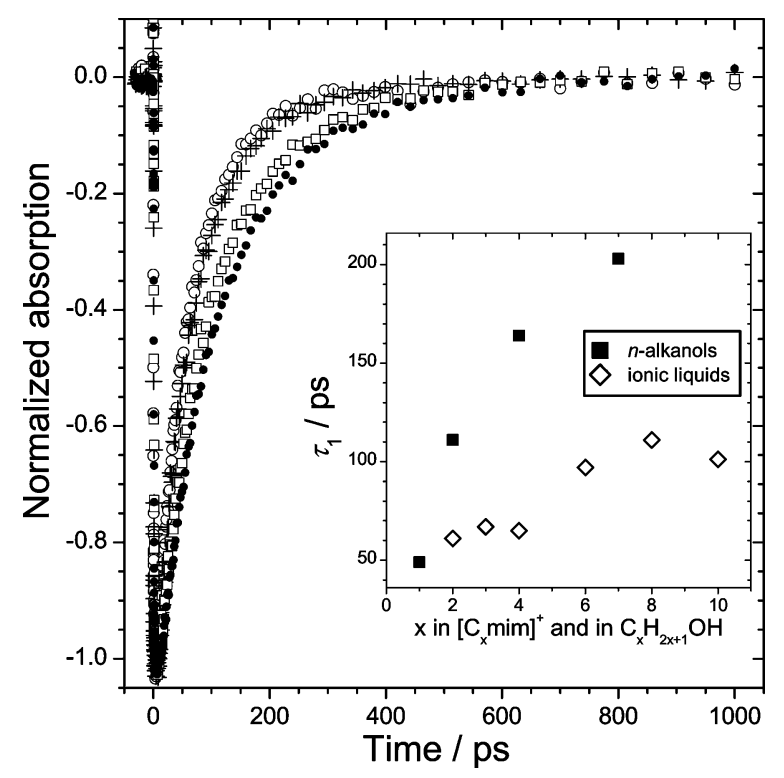

Figure 3. Examples of time-resolved transient absorption/stimulated emission signals for $12^{\prime}$-apo- $\beta$-carotenoic- $12^{\prime}$-acid in ionic liquids at 298 K. Different symbols represent different imidazolium cations of ionic liquids with the same $\left[\mathrm{Tf}_{2} \mathrm{~N}\right]^{-}$anion: (O) $\left[\mathrm{C}_{2} \mathrm{mim}\right]^{+},(+)\left[\mathrm{C}_{3^{-}}\right.$ $\mathrm{mim}]^{+},(\square)\left[\mathrm{C}_{6} \mathrm{mim}\right]^{+}$, and $(\mathbf{O})\left[\mathrm{C}_{8} \mathrm{mim}\right]^{+}$. Signals are normalized to the maximum amplitude of the stimulated emission. $\lambda_{\text {pump }}=425 \mathrm{~nm}$ and $\lambda_{\text {probe }}=850 \mathrm{~nm}$. (Inset) Internal conversion time constants $\tau_{1}\left(\mathrm{~S}_{1} /\right.$ ICT $\left.\rightarrow \mathrm{S}_{0}\right)$ as a function of the alkyl chain length $x$ in $\left[\mathrm{C}_{x} \mathrm{mim}^{+}\left[\mathrm{Tf}_{2} \mathrm{~N}\right]^{-}\right.$type ionic liquids $(\diamond)$, compared to that in $n$-alkanols $(\mathbf{\square})\left(n-\mathrm{C}_{x} \mathrm{H}_{2 x+1} \mathrm{OH}\right.$ $=$ methanol, ethanol, $n$-butanol, and $n$-heptanol). For $\tau_{1}$ values, see Table 1.
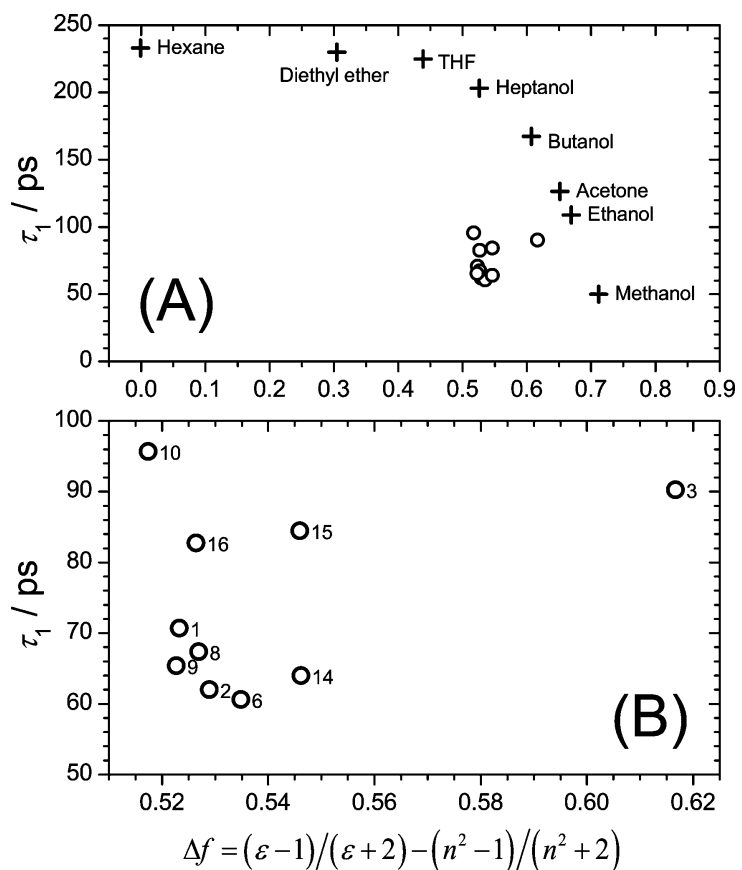

Figure 4. (A) Internal conversion time constants $\tau_{1}$ of $12^{\prime}$-apo- $\beta$ carotenoic-12'-acid in ionic liquids $(O)$ and various organic solvents $(+)$ as a function of the solvent polarity function $\Delta f$ at $298 \mathrm{~K}$ based on the $\epsilon$ values from ref 57; see also Table 1. (B) Data in ionic liquids are shown on an enlarged scale over the range $\Delta f=0.510-0.625$. The labels of the ionic liquids are consistent with the numbering scheme in Table 1.

dependent maxima of the steady-state $S_{0} \rightarrow S_{2}$ absorption spectra are summarized in Table 1.

For a comparison with the ILs, we investigated the influence of additional electrolytes on the $\tau_{1}$ values in organic solvents. We carried out measurements of $\tau_{1}$ in ethanol and diethyl ether 
TABLE 2: Internal Conversion $\left(S_{1} / \mathrm{ICT} \rightarrow \mathrm{S}_{0}\right)$ Time Constants and Steady-State Absorption Maxima of 12'-Apo- $\beta$-carotenoic-12' -acid in Organic Solvents in the Presence of Lithium Salts

\begin{tabular}{|c|c|c|c|c|c|c|c|c|c|}
\hline solvent & salt & $\begin{array}{l}\text { concentration } \\
\left(\mathrm{mol} \mathrm{L}^{-1}\right)\end{array}$ & $\tau_{1}(\mathrm{ps})$ & $\lambda_{\max }(\mathrm{nm})$ & solvent & salt & $\begin{array}{l}\text { concentration } \\
\left(\mathrm{mol} \mathrm{L}^{-1}\right)\end{array}$ & $\tau_{1}(\mathrm{ps})$ & $\lambda_{\max }(\mathrm{nm})$ \\
\hline \multirow[t]{4}{*}{ ethanol } & $\mathrm{LiClO}_{4}$ & 0.5 & 93 & 409 & ethanol & $\mathrm{LiCl}$ & 0.5 & 108 & 407 \\
\hline & & 1 & 78 & 411 & & & 1 & 107 & 407 \\
\hline & & 2 & 53 & 414 & & & 2 & 110 & 408 \\
\hline & & 4 & 32 & 417 & ethanol & $\mathrm{LiBr}$ & 0.5 & 108 & 408 \\
\hline \multirow[t]{2}{*}{ diethyl ether } & $\mathrm{LiClO}_{4}$ & 1 & 92 & 412 & & & 1 & 101 & 408 \\
\hline & & & & & & & 2 & 92 & 410 \\
\hline
\end{tabular}

in the presence of salts, such as $\mathrm{LiClO}_{4}, \mathrm{LiCl}$, and $\mathrm{LiBr}$. Table 2 summarizes the $\tau_{1}$ values determined in these experiments as a function of salt concentration. A strong acceleration of the IC process was observed upon addition of $\mathrm{LiClO}_{4}$ to diethyl ether or ethanol, whereas this effect was much weaker for $\mathrm{LiBr}$ in ethanol and almost disappeared for $\mathrm{LiCl}$ in ethanol, see Figure 5.

In addition, we tested the influence of water on the intramolecular dynamics of $12^{\prime} \mathrm{CA}$ by deliberately adding substantial amounts of water to the ILs, ethanol, and ethanol/ $/ \mathrm{LiClO}_{4}$ solutions. In all cases, the time constants changed by less than $5 \%$ up to water levels of $\sim 10000 \mathrm{ppm}$ (by mass), which strongly suggests that water impurities have a negligible influence on our signals.

\section{Discussion}

Excited-State Dynamics of $12^{\prime} \mathbf{C A}$. Prior to discussing the dynamics of $12^{\prime} \mathrm{CA}$ in ILs we would like to briefly summarize the relevant central findings from our previous time-resolved transient absorption studies of nonradiative processes in carbonyl-substituted carotenoids including $12^{\prime} \mathrm{CA}$. Results for the ultrafast internal conversion dynamics of a series of $n^{\prime}$-apo- $\beta$ caroten- $n^{\prime}$-als $(n=4,8,12)^{63-65}$ and $n^{\prime}$-apo- $\beta$-carotenoic- $n^{\prime}$ acids $(n=8,10,12)^{52}$ in "normal" organic solvents have been obtained. This class of $\mathrm{C}=\mathrm{O}$-substituted apocarotenoids possesses a low-lying excited electronic state ("S $\mathrm{S}_{1} / \mathrm{ICT}$ ") with intramolecular charge-transfer (ICT) character, which experiences a stronger stabilization relative to the ground electronic state with increasing solvent polarity. This change in relative stabilization manifests itself in the polarity-dependent intramolecular dynamics of the $\mathrm{S}_{1} / \mathrm{ICT}$ state, which can be conveniently

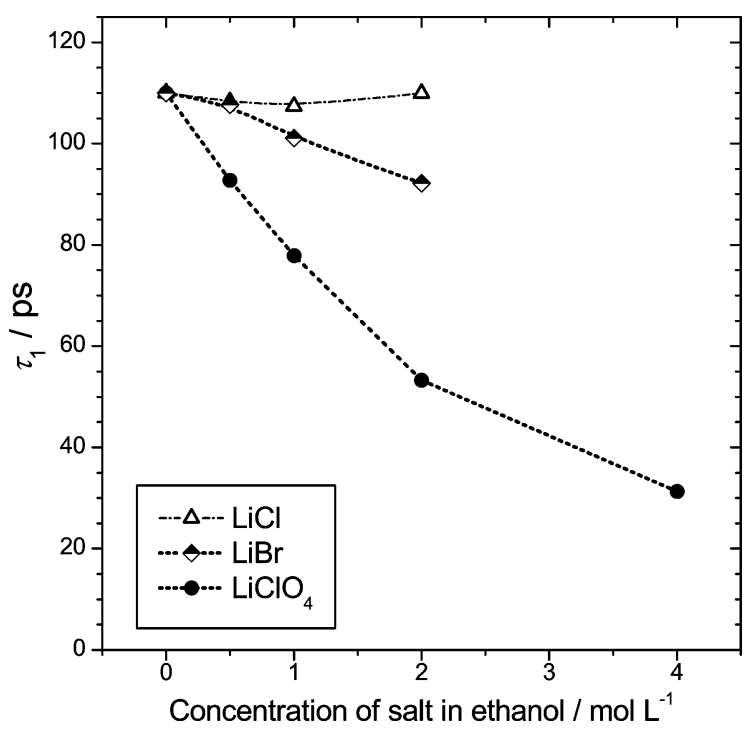

Figure 5. Effect of the addition of different lithium salts to ethanol on the internal conversion time constants $\tau_{1}$ of $12^{\prime}$-apo- $\beta$-carotenoic$12^{\prime}$-acid. probed by monitoring the decay of its characteristic stimulated emission in the near-IR region (time constant $\left.\tau_{1}\right)$. $^{52,63}$

Dependence of $\tau_{\mathbf{1}}$ on Solvent Polarity. In Figure 4, we plot $\tau_{1}$ values in terms of solvent polarity. Our previous study of the dynamics of $12^{\prime} \mathrm{CA}$ in a range of nonpolar and dipolar (both protic and aprotic) organic solvents suggested that a useful correlation can be obtained when relating the lifetime of the $\mathrm{S}_{1} / \mathrm{ICT}$ state to the solvent polarity function $\Delta f=f(\epsilon, n)$ which is defined as ${ }^{23}$

$$
\Delta f=R(\epsilon)-R(n)=\frac{\epsilon-1}{\epsilon+2}-\frac{n^{2}-1}{n^{2}+2}
$$

Here $\epsilon$ and $n$ denote the static dielectric constant and the refractive index of the solvent, respectively. The first term, $R(\epsilon)$, has electronic and nuclear polarizability (dipolar) contributions, ${ }^{23}$ whereas the second term $R(n)$ contains only the high-frequency electronic polarizability $(v \rightarrow \infty)$ contribution. Therefore, the difference between $R(\epsilon)$ and $R(n)$ can be used as an indicator of solvent dipolarity. The success of the $\Delta f$ function in establishing correlations for $12^{\prime} \mathrm{CA}$ and the closely related aldehyde $12^{\prime}$-apo- $\beta$-caroten- $12^{\prime}$-al over a wide polarity range has been already demonstrated in previous reports. ${ }^{52,63-65}$ Specifically, for $12^{\prime}$-apo- $\beta$-carotenoic- $12^{\prime}$-acid $\left(12^{\prime} \mathrm{CA}\right) \tau_{1}$ values are insensitive to the change of solvent polarity for nonpolar to midpolar solvents. However, a strong reduction of the $\tau_{1}$ values is observed in more polar solvents. For $12^{\prime} \mathrm{CA}$ the plateau of solvent-independent time constants $\left(\tau_{1} \approx 220 \mathrm{ps}\right)$ extends relatively far into the midpolar range before showing a steep decay reaching $\tau_{1}=49 \mathrm{ps}$ in methanol (Figure 4). ${ }^{52}$ The decrease in $\tau_{1}$ can be qualitatively understood in terms of the reduction of the $\mathrm{S}_{1} / \mathrm{ICT}-\mathrm{S}_{0}$ energy difference in the framework of an energy gap law approach. ${ }^{64,66,67}$

It is instructive to compare how the present $\tau_{1}$ values for $12^{\prime} \mathrm{CA}$ in different ILs fit into this correlation. Therefore, we measured the required refractive indices for the different ILs (see Table 1). In addition, we found very good agreement with the refractive index data available in the literature. Static dielectric constants of the ionic liquids are also required for establishing the $\tau_{1}-\Delta f$ correlation. Unfortunately, this important quantity is not frequently available in the literature, but recently there is a growing collection of experimental frequency-dependent $\epsilon$ values for some ionic liquids obtained using dielectric spectroscopy by Weingärtner and co-workers and also Buchner, Hefter, and co-workers (for a compilation, see Table 1). ${ }^{35-40,68,69}$ Static dielectric constants can be estimated from their experiments by extrapolation toward the zerofrequency limit $(v \rightarrow 0)$.

Upon inspection of Figure 4 two main differences should be noted. (1) Although there are considerable changes with respect to chemical identity, structure, and ion composition of the ILs, all $\tau_{1}$ values fall into a rather narrow and well-defined range and are close to the values for ethanol and methanol. In addition, as also shown in Figure 3, the $\tau_{1}$ values in organic dipolar 
solvents show a strong dependence on the solvent dipolarity in this range, for example, 203 ps in $n$-heptanol down to 49 ps in methanol. This corresponds to a 4-fold decrease over the $\Delta f$ range from 0.526 to 0.711 . In contrast, less than one-half of this change in $\tau_{1}$ was observed upon varying the $n$-alkyl chain length in the $\left[\mathrm{C}_{x} \mathrm{mim}\right]^{+}\left[\mathrm{Tf}_{2} \mathrm{~N}\right]^{-}$series. The results indicate that in ILs the relative stabilization of the $\mathrm{S}_{1} / \mathrm{ICT}$ state of the $12^{\prime} \mathrm{CA}$ probe molecule is primarily governed by a similar type of interaction, very likely dominated by electrostatic interactions between the "negative end" of the probe dipole (e.g., the carbonyl function) and the IL cation charge. In contrast, other changes due to solvent structure or variation of the chemical identity of the cations and anions only provide a fairly small incremental stabilization or destabilization of the $\mathrm{S}_{1} / \mathrm{ICT}$ state with respect to the ground electronic state $\mathrm{S}_{0}$ of the $12^{\prime} \mathrm{CA}$ probe molecule.

An idea about the type of stabilization of the $\mathrm{S}_{1} / \mathrm{ICT}$ state of $12^{\prime} \mathrm{CA}$ and related probes can be obtained from preliminary DFT/TDDFT calculations in our groups for the ground and excited electronic states of the related $12^{\prime}$-apo- $\beta$-caroten-12'al. The calculations suggest that a substantial dipole moment exists already in the $\mathrm{S}_{0}$ state $(8 \mathrm{D})$, which strongly increases upon formation of the $\mathrm{CT}$ state $(\sim 51 \mathrm{D})$ due to a substantial charge shift along the polyene chain toward the carbonyl group and the adjacent conjugated $\mathrm{C}=\mathrm{C}$ double bonds. It is reasonable to assume that a favorable interaction of IL cation(s) specifically with the carbonyl end of the molecule is already present in $\mathrm{S}_{0}$, which results in considerable electrostatic stabilization of the probe by the cation charge. The stabilization will strongly increase upon formation of the $\mathrm{S}_{1} / \mathrm{ICT}$ state. Inertial cation motions on an ultrafast time scale might provide additional stabilization of the larger dipole. Such a mechanism would be consistent with the results of Kerr-gated emission spectroscopy of the solvation response of probe molecules like trans-4dimethylamino-4'-cyanostilbene (DCS) in imidazolium and pyrrolidinium ILs. ${ }^{22}$

(2) The $\tau_{1}$ values of $12^{\prime} \mathrm{CA}$ in ILs are much smaller (i.e., the internal conversion processes are much faster) than what one would expect from the behavior of the probe molecule in dipolar solvents in the same $\Delta f$ range. Since $\Delta f$ is based on the static dielectric constant and the refractive index of the solvent, the deviation of $\tau_{1}$ values in Figure 4 simply implies that the probe experiences a considerably more polar surrounding than what is extrapolated on the basis of the macroscopic quantities $\epsilon$ and $n$.

For "micropolarity probes" like $12^{\prime} \mathrm{CA}$ used in the present study, short-range electrostatic interactions of the probe with ions (here mainly the charge density of the cations) or formation of specific solute-solvent complexes appear to play a key role. It is therefore not surprising that the correlation between $\tau_{1}$ and $\Delta f$, which is observed in normal organic solvents, does not perform well for ionic liquids (Figure 4) due to the different character of the electrostatics involved. Our $\tau_{1}$ values of $12^{\prime} \mathrm{CA}$ in ILs could be empirically matched with the correlation in dipolar solvents if one considers a larger "effective local dielectric constant" $\epsilon_{\text {eff }}$, i.e., $R\left(\epsilon_{\text {eff }}\right)$ approaches relatively close to unity and therefore $\Delta f_{\text {eff }} \rightarrow 1-R(n)$. Maroncelli and coworkers reported similar deviations, in their case for solvation free energies and solvent reorganization energies of Coumarin 153 in ionic liquids from the good correlation of these quantities with the reaction field factor $R(\epsilon)$ in dipolar solvents. ${ }^{23}$

Dependence of $\tau_{\mathbf{1}}$ on Cation Radius. We also investigated additional correlations between $\tau_{1}$ and other empirical scales based on ion density or mean ion separation which have been

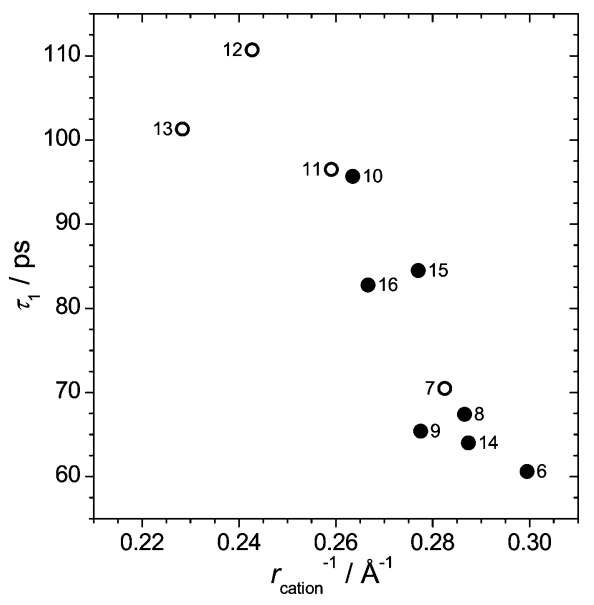

Figure 6. Dependence of $\tau_{1}$ for $12^{\prime}$-apo- $\beta$-carotenoic-12'-acid in $\left[\mathrm{Tf}_{2} \mathrm{~N}\right]^{-}$-based ionic liquids on the cation radius (for numbering see Table 1). The cation radii are from the literature ()$^{36,38,39}$ or extrapolations (O). For details, see the text.

used, e.g., for fitting the noninertial component of the solvation time of Coumarin 153 in ILs. ${ }^{23}$ For example, in Figure 6 we apply a simple correlation between $\tau_{1}$ and the reciprocal cation radius for a series of ILs with the same $\left[\mathrm{Tf}_{2} \mathrm{~N}\right]^{-}$anion partner. Where available, the cation radii were taken from the literature. ${ }^{36,38,39}$ Radii for the longer chain $\left[\mathrm{C}_{x} \mathrm{mim}\right]^{+}$cations $(x=6$, $8,10)$ were extrapolated using a value of $\Delta r_{\text {cation }}=0.13 \AA$ per additional $\mathrm{CH}_{2}$ group estimated from the literature values $r_{\text {cation }}$ for $\left[\mathrm{C}_{2} \mathrm{mim}\right]^{+},\left[\mathrm{C}_{3} \mathrm{mim}\right]^{+}$, and $\left[\mathrm{C}_{4} \mathrm{mim}\right]^{+}$. The radius of $\left[\mathrm{C}_{2^{-}}\right.$ mmim $]^{+}$was estimated from the value for $\left[\mathrm{C}_{2} \mathrm{mim}\right]^{+}$and the difference $\Delta r_{\text {cation }}=0.20 \AA$ between $\left[\mathrm{C}_{4} \mathrm{mmim}\right]^{+}$and $\left[\mathrm{C}_{4} \mathrm{mim}\right]^{+}$. If electrostatic interactions are involved in the stabilization of the $\mathrm{S}_{1} / \mathrm{ICT}$ state of $12^{\prime} \mathrm{CA}$ in ILs, one would expect an improved stabilization (i.e., decrease of $\tau_{1}$ ) with smaller cation radius. Figure 6 shows that such a correlation is indeed approximately fulfilled. Particularly encouraging is the fact that different types of cations, like imidazolium with different substituents (6-13), triethylsulfonium (14), and tetraalkylammonium $(15,16)$, appear to fall on one line. Of course, such a simple correlation is not expected to work perfectly because it neglects additional factors like the anisotropy of the molecular shape and the different charge distribution of the cations.

Influence of Methylation at the $\mathrm{C} 2$ Position of the Imidazolium Cation on $\tau_{1}$. In the case of imidazolium cations, calculations suggest that favorable sites for interaction with anions and other nucleophiles are located in the vicinity of the imidazolium hydrogen atoms. ${ }^{70-72} \mathrm{NMR}$ experiments show that, in the case of $\left[\mathrm{C}_{2} \mathrm{mim}\right]^{+}\left[\mathrm{N}(\mathrm{CN})_{2}\right]^{-}$and $\left[\mathrm{C}_{2} \mathrm{mim}\right]^{+}\left[\mathrm{Tf}_{2} \mathrm{~N}\right]^{-}, \mathrm{H} / \mathrm{D}$ exchange takes place only for the hydrogen bound to $\mathrm{C} 2$ (located between the two ring nitrogen atoms), whereas no exchange occurs for the other two ring hydrogen atoms. ${ }^{40}$ However, the acidity is very small ( $\mathrm{p} K_{\mathrm{a}} \approx 23$ ), compare, e.g., to $\mathrm{p} K_{\mathrm{a}} \approx 15.5$ and 16 for methanol and ethanol, respectively. ${ }^{73,74}$ Results from DFT calculations suggest that interactions between the imidazolium $\mathrm{H}$ atoms (H2, H4, H5) and anions should not be termed as hydrogen bonding because the hydrogen-anion distance is rather long and the $\mathrm{C}-\mathrm{H}-$ anion bond angle deviates significantly from $180^{\circ} .{ }^{70,71}$ Even more important, Tsuzuki et al. demonstrated in their MP2 calculations that electrostatic interactions dominate when the anion approaches the imidazolium cation (slightly above or below the ring plane) toward the midpoint between the two nitrogen atoms of the imidazolium cation (which is close to the center of its positive charge). They also found that the orientational dependence of the interaction 
energy is small and that the magnitude of the interaction energy varies only weakly for the anions $\mathrm{Cl}^{-}, \mathrm{Br}^{-},\left[\mathrm{BF}_{4}\right]^{-}$, and $\left[\mathrm{PF}_{6}\right]^{-} .75$

Methylation at the $\mathrm{C} 2$ position should therefore at least partially impair the capability of the imidazolium cation to coordinate with nucleophiles due to unfavorable steric congestion. If some sort of closer interaction between the positive imidazolium and the "negative end" of the $12^{\prime} \mathrm{CA}$ probe is important for stabilizing the $\mathrm{S}_{1} / \mathrm{ICT}$ state, one would expect an increase of $\tau_{1}$ upon methylation at the $\mathrm{C} 2$ position. Indeed, we found an increase of $\tau_{1}$ when changing from $\left[\mathrm{C}_{4} \mathrm{mim}\right]^{+}\left[\mathrm{Tf}_{2} \mathrm{~N}\right]^{-}$ (65 ps) to $\left[\mathrm{C}_{4} \mathrm{mmim}\right]^{+}\left[\mathrm{Tf}_{2} \mathrm{~N}\right]^{-}(96 \mathrm{ps})$, see Figure 4 and Table 1. A similar but smaller change was found for the shorter chain analogue $\left[\mathrm{C}_{2} \mathrm{mim}\right]^{+}\left[\mathrm{Tf}_{2} \mathrm{~N}\right]^{-}(61 \mathrm{ps})$ and its methylated derivative $\left[\mathrm{C}_{2} \mathrm{mmim}\right]^{+}\left[\mathrm{Tf}_{2} \mathrm{~N}\right]^{-}$(71 ps). In the C2-methylated ILs the $12^{\prime} \mathrm{CA}$ probe therefore experiences what could be loosely termed as a "less polar environment". Note that a qualitatively similar effect has been also observed when using Reichardt's pyridinium $N$-phenolate betaine dye no. 30 as a solvatochromic probe. For instance, one obtains in terms of the normalized $E_{T}{ }^{N}$ polarity scale $\left[\mathrm{C}_{4} \mathrm{mim}\right]^{+}\left[\mathrm{Tf}_{2} \mathrm{~N}\right]^{-}(0.596)$ and $\left[\mathrm{C}_{4} \mathrm{mmim}\right]^{+}\left[\mathrm{Tf}_{2} \mathrm{~N}\right]^{-}(0.546)$, $\left[\mathrm{C}_{8} \mathrm{mim}\right]^{+}\left[\mathrm{Tf}_{2} \mathrm{~N}\right]^{-}(0.630)$ and $\left[\mathrm{C}_{8} \mathrm{mmim}\right]^{+}\left[\mathrm{Tf}_{2} \mathrm{~N}\right]^{-}(0.525)$, where the higher number denotes a "higher polarity" of the solvent. ${ }^{43}$ In that case, coordination of the dye with the imidazolium cation is probably changed upon methylation at the $\mathrm{C} 2$ position. This affects the electrostatic interactions between the solvent and the probe molecule in the $S_{0}$ and $S_{1}$ electronic states, which appear to be the dominant contributions determining the absorption shift of the betaine-30 dye. ${ }^{76}$

Effect of $\boldsymbol{n}$-Alkyl Chain Length in $\left[\mathrm{C}_{x} \mathrm{mim}\right]^{+}$Cations. Recent results from dielectric spectroscopy for a series of $\left[\mathrm{C}_{x} \mathrm{mim}\right]^{+}\left[\mathrm{Tf}_{2} \mathrm{~N}\right]^{-}$salts $(x=2,3,4,5)$ show a smooth decrease of the static dielectric constant $\epsilon$ with increasing $n$-alkyl chain length on the imidazolium cation $(12.3>11.8>11.6>$ 11.5). ${ }^{36-38}$ In contrast, measurements aiming at quantifying the polarity of the $\left[\mathrm{C}_{x} \mathrm{mim}\right]^{+}\left[\mathrm{Tf}_{2} \mathrm{~N}\right]^{-}$series $(x=2,3,4,6,8$, and 10) using Reichardt's dye show no systematic ordering in terms of the normalized $E_{\mathrm{T}}{ }^{\mathrm{N}}$ polarity scale: $0.676,0.654,0.596,0.654$, 0.630 , and 0.627 , respectively. ${ }^{43}$

It is instructive to compare these results with the time constants provided by the "dynamics probe" $12^{\prime} \mathrm{CA}$ (Table 1, Figures 3 and 4). On average we observed an increase of the internal conversion times with increasing length of the $n$-alkyl chain in the $\left[\mathrm{C}_{x} \mathrm{mim}\right]^{+}\left[\mathrm{Tf}_{2} \mathrm{~N}\right]^{-}$series with $x=2,3,4,6,8$, and 10. Slight deviations from this trend were found for the $n$-butyl species (similar $\tau_{1}$ as for $n$-propyl) and at large $x$, where the $\tau_{1}$ values appear to level off. The increase in $\tau_{1}$ is much weaker than in the sequence of the $n$-alkanol organic solvents (see the inset of Figure 3). The latter ones therefore appear to become much "less polar" than the corresponding substituted imidazolium-based ILs.

As mentioned before, in the case of the ILs the electrostatic interaction between the "negative end" of the $12^{\prime} \mathrm{CA}$ probe and the cation charge is likely the key factor controlling the relative stabilization of the $\mathrm{S}_{1} / \mathrm{ICT}$ state and therefore the magnitude of $\tau_{1}$. The orientational dependence of the interaction energy between the cation and the nucleophilic tail of the probe molecule is expected to be small. ${ }^{75}$ Therefore, while steric congestion will increase as chain length becomes larger, there are less but still enough favorable solvation sites available on both sides of the ring plane, which will lead to stabilization of the $\mathrm{S}_{1} / \mathrm{ICT}$ state of the $12^{\prime} \mathrm{CA}$ probe. Induction effects, i.e., transfer of electron density from long $n$-alkyl groups toward the ring, are probably less important. Interestingly, Amyes, Diver, and co-workers even found a slightly larger acidity for the substituted 1,3-dimethylimidazolium cation $\left(\mathrm{p} K_{\mathrm{a}}=23.0\right)$ than for the bare imidazolium cation $\left(\mathrm{p} K_{\mathrm{a}}=23.8\right) .{ }^{73}$ Introduction of longer $n$-alkyl chains therefore apparently leads to stronger localization of the positive charge on the $\mathrm{C} 2-\mathrm{H} 2$ unit of the imidazolium ring, which still enables a favorable interaction with the probe molecule. On the other hand, dispersive interactions between the polyene chain of the $12^{\prime} \mathrm{CA}$ probe and a longer $n$-alkyl chain of the imidazolium cation could produce some van der Waals bound 12'CA-cation conformers, where the cation-induced stabilization of the $\mathrm{S}_{1} / \mathrm{ICT}$ state might be reduced, leading to an increase of $\tau_{1}$.

Drawing a comparison with our results for $n$-alkanols, we believe that efficient directional hydrogen bonds, which could stabilize the $12^{\prime} \mathrm{CA}$ probe molecule, are more difficult to establish for longer chain than for shorter chain species. Appreciable van der Waals interactions between the polyene chain of $12^{\prime} \mathrm{CA}$ and the alkyl group of long-chain $n$-alkanols will disturb $\mathrm{H}$-bond formation and certainly lead to a pronounced reduction of the $\mathrm{H}$-bonding capability. At the same time inductive effects, i.e., a transfer of electron density from the $n$-alkyl group to the $\mathrm{OH}$ group, will reduce the polarization of the $\mathrm{OH}$ bond and therefore its capability to form hydrogen bonds.

In summary, an increase of the $n$-alkyl chain length for the imidazolium-based ILs and $n$-alkanols leads to a reduced relative stabilization of the $\mathrm{S}_{1} / \mathrm{ICT}$ state (i.e., larger time constants $\tau_{1}$ ) in both cases. However, the effect is much less pronounced for ILs, mainly because of the efficient and less directional cation-dipole interaction which still provides appreciable stabilization of the $12^{\prime} \mathrm{CA}$ probe despite the increased steric congestion.

Dependence on Cation Type. We investigated three nonimidazolium-type ionic liquids, $\left[\mathrm{Et}_{3} \mathrm{~S}\right]^{+}\left[\mathrm{Tf}_{2} \mathrm{~N}\right]^{-},\left[\mathrm{BuMe}_{3} \mathrm{~N}\right]^{+}$$\left[\mathrm{Tf}_{2} \mathrm{~N}\right]^{-}$, and $[\mathrm{BuMePyr}]^{+}\left[\mathrm{Tf}_{2} \mathrm{~N}\right]^{-}$with the same anion partner, to find out how cations with the same total charge but different chemical constitution influence the probe dynamics. As seen in the inset of Figure 4 and Table 1, $\tau_{1}$ values for these three ionic liquids change in the order $\tau_{1}\left(\left[\mathrm{Et}_{3} \mathrm{~S}\right]^{+}\left[\mathrm{Tf}_{2} \mathrm{~N}\right]^{-}\right)<$ $\tau_{1}\left([\mathrm{BuMePyr}]^{+}\left[\mathrm{Tf}_{2} \mathrm{~N}\right]^{-}\right) \approx \tau_{1}\left(\left[\mathrm{BuMe}_{3} \mathrm{~N}\right]^{+}\left[\mathrm{Tf}_{2} \mathrm{~N}\right]^{-}\right)$. Ab initio calculations show that in the case of tetraalkylammonium species the positive charge is substantially delocalized over the alkyl ligands. ${ }^{77}$ The relatively large $\tau_{1}$ values for both cations are therefore understandable because the probe cannot interact so favorably with the more delocalized and diffuse positive charge. In contrast, for the triethylsulfonium cation one expects the positive charge to be preferentially localized on the sulfur atom on the basis of ab initio calculations for the closely related trimethylsulfonium cation. ${ }^{78}$ The electrostatic interactions between $\left[\mathrm{Et}_{3} \mathrm{~S}\right]^{+}$and the $12^{\prime} \mathrm{CA}$ probe will therefore be stronger, leading to an increased relative stabilization of $\mathrm{S}_{1} / \mathrm{ICT}$ relative to $S_{0}$. This results in an acceleration of the internal conversion rate (i.e., smaller $\tau_{1}$ ).

Our findings can be compared with results from dielectric spectroscopy in the same ILs obtained by Weingärtner and coworkers (Table 1). ${ }^{39}$ They report pronounced differences regarding the high-frequency portion of the dielectric spectrum between imidazolium- and non-imidazolium-based ILs having the same counteranion. The extrapolated static dielectric constants for the three ionic liquids are relatively similar and arranged in the order $\epsilon\left([\mathrm{BuMePyr}]^{+}\left[\mathrm{Tf}_{2} \mathrm{~N}\right]^{-}\right)<\epsilon\left(\left[\mathrm{BuMe} \mathrm{N}_{3}\right]^{+}\right.$ $\left.\left[\mathrm{Tf}_{2} \mathrm{~N}\right]^{-}\right)<\epsilon\left(\left[\mathrm{Et}_{3} \mathrm{~S}\right]^{+}\left[\mathrm{Tf}_{2} \mathrm{~N}\right]^{-}\right)$. As in the current measurements using the $12^{\prime} \mathrm{CA}$ probe, the triethylsulfonium IL is the most polar one. In contrast, dielectric spectroscopy suggests a polarity difference between the two tetraalkylammonium ILs, whereas 
the $12^{\prime} \mathrm{CA}$ probe finds almost identical behavior with respect to micropolarity.

Additional polarity estimates on the basis of Reichardt's betaine dye no. 30 are also available for the tetraalkylammonium ILs (but not for the triethylsulfonium species). On the reduced $E_{\mathrm{T}}{ }^{\mathrm{N}}$ scale one finds $0.540\left([\mathrm{BuMePyr}]^{+}\left[\mathrm{Tf}_{2} \mathrm{~N}\right]^{-}\right)<$ $0.574\left(\left[\mathrm{BuMe}_{3} \mathrm{~N}\right]^{+}\left[\mathrm{Tf}_{2} \mathrm{~N}\right]^{-}\right)<0.596\left(\left[\mathrm{C}_{4} \mathrm{mim}\right]^{+}\left[\mathrm{Tf}_{2} \mathrm{~N}\right]^{-}\right) .^{5}$ While the reduced polarity with respect to the imidazolium species is consistent with the results of the $12^{\prime} \mathrm{CA}$ probe, Reichardt's dye also finds a difference between the two tetraalkylammonium salts, similar to the results of dielectric spectroscopy.

Influence of Different Anions. Our experimental data also allow us to investigate the influence of anion variation on the time constant $\tau_{1}$ for two series of imidazolium cations. In the case of $\left[\mathrm{C}_{4} \mathrm{mim}\right]^{+}$the dependence of $\tau_{1}$ on the type of anion is weak and values of $71,62,67$, and 65 ps are found for $\left[\mathrm{BF}_{4}\right]^{-}$, $\left[\mathrm{PF}_{6}\right]^{-},\left[\mathrm{N}(\mathrm{CN})_{2}\right]^{-}$, and $\left[\mathrm{Tf}_{2} \mathrm{~N}\right]^{-}$, respectively. In the $\left[\mathrm{C}_{2} \mathrm{mim}\right]^{+}$ series the value for $\left[\mathrm{N}(\mathrm{CN})_{2}\right]^{-}(43 \mathrm{ps})$ is smaller than for $\left[\mathrm{Tf}_{2} \mathrm{~N}\right]^{-}$ (61 ps). A particularly strong increase to 90 ps (i.e., "lower polarity") is found for $\left[\mathrm{C}_{2} \mathrm{mim}\right]^{+}\left[\mathrm{EtOSO}_{3}\right]^{-}$, the most asymmetric anion in the series which has a more localized negative charge. This effect is remarkable, especially when considering the static dielectric constant reported by Weingärtner (27.9), which is the highest experimental $\epsilon$ value found for an IL so far. ${ }^{37}$ The particularly large $\epsilon$ value can be rationalized on the basis of MD simulations of Schröder et al. for a similar system. They extrapolated a relatively large value for the static dielectric constant of $\left[\mathrm{C}_{4} \mathrm{mim}\right]^{+}\left[\mathrm{CF}_{3} \mathrm{COO}\right]^{-}(\epsilon=28.2)$, an IL with an anion, which also has a fairly localized charge and is therefore similar to $\left[\mathrm{EtOSO}_{3}\right]^{-} .{ }^{79}$ Their analysis using the concept of the time correlation function for a collective rotational dipole moment provided values of $16.7,6.1$, and 2.7 for the contributions of the cation-cation, anion-anion, and cation-anion cross-correlation terms to $\epsilon$. In contrast, for $\left[\mathrm{C}_{4} \mathrm{mim}\right]^{+}\left[\mathrm{BF}_{4}\right]^{-}$ they found a much smaller cation-cation term (9.4) with a negligible anion-anion contribution from the spherically symmetric $\left[\mathrm{BF}_{4}\right]^{-} .{ }^{71,79,80}$ Schröder et al. interpret this fact by a strengthening of the parallel orientation of the cationic dipole field through the dipole field of the anions in the IL network. A stronger correlation and interaction of the anions with the cations might be also the key to understand the slower relaxation of $12^{\prime} \mathrm{CA}$ in $\left[\mathrm{C}_{2} \mathrm{mim}\right]^{+}\left[\mathrm{EtOSO}_{3}\right]^{-}$. One reasonable scenario would be that there is a particularly efficient competition of the IL anions with the $12^{\prime} \mathrm{CA}$ probe for coordination with the cation.

Temperature Dependence of $\tau_{1}$. We found an increase of the IC rate constant of $12^{\prime} \mathrm{CA}$ with increasing temperature in the range $298-348 \mathrm{~K}$ in $[\mathrm{BuMePyr}]^{+}\left[\mathrm{Tf}_{2} \mathrm{~N}\right]^{-}$, see Table 1 . The results were parametrized in an Arrhenius-type representation, which yielded an "apparent experimental activation energy" $E_{\mathrm{a}, \exp }$ of $8 \mathrm{~kJ} \mathrm{~mol}^{-1}$. In ILs we cannot simply correct $E_{\mathrm{a}, \exp }$ for a temperature-dependent change of $\Delta f(T)$ itself (i.e., $\epsilon(T)$ and $n(T)$ ) because there is no satisfactory correlation with this quantity in contrast to organic solvents. To our knowledge, only two examples of $\epsilon(T)$ tabulations are available in the temperature range $288-318 \mathrm{~K}:\left[\mathrm{C}_{2} \mathrm{mim}\right]^{+}\left[\mathrm{Tf}_{2} \mathrm{~N}\right]^{-} \quad(12.5 \rightarrow 11.7)$ and $\left[\mathrm{C}_{4} \mathrm{mim}\right]^{+}\left[\mathrm{Tf}_{2} \mathrm{~N}\right]^{-}(11.6 \rightarrow 11.7){ }^{38}$ We therefore compare the $E_{\mathrm{a} \text {,exp }}$ without further correction with respect to the change in $\epsilon(T)$. Similar $E_{\mathrm{a}, \exp }$ values for $12^{\prime}$-apo- $\beta$-caroten- $12^{\prime}$-al in the range $283-333 \mathrm{~K}$ were found in organic solvents. ${ }^{63}$ There are good arguments that the main contribution to this temperature dependence can be assigned to the energy dependence of the IC process (see ref 81).
It is worthwhile considering other effects which might influence the temperature dependence of $\tau_{1}$. The presence of a viscosity-dependent molecular rearrangement accompanying or facilitating the intramolecular decay (like a conformational relaxation or internal rotation) could have an impact on $\tau_{1}$. Viscosities of organic solvents and ILs decrease with increasing temperature, so this would accelerate the internal conversion process. However, in our current study no clear correlation between $\tau_{1}$ and viscosity could be established for organic solvents and ILs. Moreover, preliminary DFT and TDDFT calculations by us for the closely related $12^{\prime}$-apo- $\beta$-caroten- $12^{\prime}$ al suggest that formation and decay of the $\mathrm{S}_{1} / \mathrm{ICT}$ state is accompanied by only marginal changes in the molecular structure.

We finally note that the increasing blue shift of the static absorption spectrum of $12^{\prime} \mathrm{CA}$ in $[\mathrm{BuMePyr}]^{+}\left[\mathrm{Tf}_{2} \mathrm{~N}\right]^{-}$with increasing temperature correlates well with the decrease of solvent density. Such a thermochromic effect was also observed for other carotenoids. ${ }^{82}$

Addition of Lithium Salts to Solutions of $12^{\prime} \mathrm{CA}$ in Organic Solvents. Our results for the addition of salts to $12^{\prime} \mathrm{CA}$ solutions in ethanol or diethyl ether can be most conveniently interpreted when considering previous experimental work on the behavior of organic probe molecules in ionic solutions. ${ }^{83-87}$ Chapman and Maroncelli used steady-state and time-resolved emission spectroscopy to investigate the behavior of several solvatochromic probe molecules (Coumarin 102, Coumarin 153, Prodan, 4-aminophthalimide) in a wide range of salt solutions (perchlorates with $\mathrm{Li}^{+}, \mathrm{Na}^{+}, \mathrm{Mg}^{2+}, \mathrm{Ca}^{2+}, \mathrm{Sr}^{2+}$, and $\mathrm{Ba}^{2+}$ as counterions). ${ }^{85}$ They carried out particularly detailed experiments for Coumarin 102 (C102), which features a carbonyl group in conjugation with an aromatic system. Similar to their observations for $\mathrm{C} 102$ in perchlorate salt solutions, ${ }^{85}$ we find that addition of $\mathrm{LiClO}_{4}$ induces a frequency shift in the $12^{\prime} \mathrm{CA}$ steady-state absorption spectrum, and the spectral shape and width are not changing drastically. The frequency shift appears to be a smooth function of salt concentration. In addition, we find that for a given concentration of $\mathrm{LiClO}_{4}$, the stronger the probe-solvent interactions, as measured by the red shift of the absorption maximum of $12^{\prime} \mathrm{CA}$ in the pure solvent, the smaller the ion-induced shift. Taking $1 \mathrm{M}$ solutions of $\mathrm{LiClO}_{4}$ in diethyl ether and ethanol as examples (Table 2), the shift for diethyl ether is $\Delta \lambda=+14 \mathrm{~nm}$ whereas for ethanol it is only $+4 \mathrm{~nm}$ relative to the position of the band maximum in the pure solvents ( $\lambda_{\max }=398$ and $407 \mathrm{~nm}$, respectively). Following ref 85, it is likely more appropriate to assume that ionic solvation of such probes involves specific associations with $\mathrm{Li}^{+}$ion(s) rather than nonspecific interactions of the probe with a diffuse ion atmosphere. The presence of specific interactions between carbonyl compounds and $\mathrm{Li}^{+}$ions was also suggested by recent investigations of Pocker and Spyridis of the keto-enol tautomeric equilibrium of 2,4-pentanedione. ${ }^{88}$ For instance, while in pure diethyl ether the keto content of the diketone is only $5 \%$, it increases to $84.5 \%$ in $4.14 \mathrm{M} \mathrm{LiClO}_{4}$-diethyl ether solution. Because of its considerable charge density, the $\mathrm{Li}^{+}$ion presumably coordinates favorably with the two keto carbonyl groups (acting as a Lewis acid $^{89}$ ), thereby shifting the equilibrium toward the diketone. Such specific interactions of $\mathrm{Li}^{+}$cations were also suggested for Reichardt's dye and other dipolar organic molecules in $\mathrm{LiClO}_{4}$ - diethyl ether solutions. ${ }^{90,91}$

Addition of $\mathrm{LiClO}_{4}$ has a remarkably strong effect on the intramolecular relaxation of the $\mathrm{S}_{1} / \mathrm{ICT}$ state of $12^{\prime} \mathrm{CA} . \tau_{1}$ decreased from 230 (in pure diethyl ether) to 92 ps after adding $1 \mathrm{M} \mathrm{LiClO}_{4}$. In ethanol, $\tau_{1}$ changed from 109 (pure solvent) to 
$78\left(1 \mathrm{M} \mathrm{LiClO}_{4}\right)$ and 32 ps $\left(4 \mathrm{M} \mathrm{LiClO}_{4}\right)$. The observed acceleration of the internal conversion process (decrease of $\tau_{1}$ ) in $\mathrm{LiClO}_{4}$ salt solutions is likely due to a favorable interaction of the carbonyl oxygen ("negative end" of the excited-state dipole) with $\mathrm{a} \mathrm{Li}^{+}$cation, which results in a considerable stabilization of the $\mathrm{S}_{1} / \mathrm{ICT}$ state. This stabilization increases with increasing salt concentration but appears to saturate slightly at the highest salt concentrations (Table 2 and Figure 5). Note that an analogous acceleration of nonradiative relaxation processes has been found by Thompson and Simon for 3-aminofluorenone in acetonitrile solutions when adding $\mathrm{LiClO}_{4}$ up to concentrations of $1 \mathrm{M}^{92}$

In the case of the $\mathrm{C} 102$ probe, the type of the counteranion only has a marginal influence on the spectral and dynamic characteristics of the probe molecule. ${ }^{85}$ However, in our experiments we find substantial differences upon addition of $\mathrm{LiClO}_{4}, \mathrm{LiBr}$, and $\mathrm{LiCl}$ salts to ethanol (Table 2, Figure 5). While a strong decrease of $\tau_{1}$ was observed in the presence of $\mathrm{LiClO}_{4}(0.5-4 \mathrm{M})$, it was mild upon adding $\mathrm{LiBr}(0.5-2 \mathrm{M})$ and there was practically no change when adding $\mathrm{LiCl}(0.5-2$ $\mathrm{M})$. Interestingly, Table 2 shows that the absorption maximum of the $S_{0} \rightarrow S_{2}$ transition exhibits a qualitatively similar behavior (smaller red shift in the case of $\mathrm{LiBr}$ and no red shift compared to pure ethanol in the case of $\mathrm{LiCl}$ ). A lack of spectral shift relative to pure ethanol would be consistent with the interpretation that the $\mathrm{Li}^{+}-$probe interactions are much weaker. This would be also consistent with the insensitivity of $\tau_{1}$ upon $\mathrm{LiCl}$ addition. One reasonable explanation could be formation of contact ion pairs, which is known to be more efficient for $\mathrm{LiBr}$ than for $\mathrm{LiClO}_{4}$ solutions (see ref 93 for an example in acetonitrile). The ion pairs could possibly interact less favorably with the $12^{\prime} \mathrm{CA}$ probe molecule than free $\mathrm{Li}^{+}$ions.

\section{Conclusions}

We presented results for the intramolecular dynamics of 12'apo- $\beta$-carotenoic- $12^{\prime}$-acid $\left(12^{\prime} \mathrm{CA}\right)$ in ionic liquids, which appears to be a sensitive microscopic probe for reporting information on the local environment and micropolarity in ILs. The lifetime of the polar $\mathrm{S}_{1} / \mathrm{ICT}$ state, which is correlated with its energetic stabilization relative to $S_{0}$, is taken as an indicator. Interestingly, although we investigated a number of ILs with different cations (imidazolium, pyrrolidinium, tetraalkylammonium), various anions, and substituents of varying chain length, we observe only a mild change of the microscopic polarity. The lifetime $\tau_{1}$ of the $\mathrm{S}_{1} / \mathrm{ICT}$ state of the probe in the ILs is always in the range $40-110 \mathrm{ps}$ and thus comparable to $\tau_{1}$ in ethanol (109 ps) and methanol (49 ps). The experimental results suggest that local electrostatic interactions between the cation charge (monopole) and the probe's dipole govern the dynamics of $12^{\prime} \mathrm{CA}$ in ILs. The dominance of such electrostatic effects also provides a straightforward explanation of why simple correlations (like $\tau_{1}-\Delta f$ ), which work successfully in organic solvents, do not perform well in the case of ILs.

In general, we believe that for ultrafast nonradiative processes and unimolecular elementary reactions in ILs on the several 10 fs to picosecond time scale, electrostatic interactions of the reactants with nearby ions will be most important. This will be in particular the case when charged or polar educts, transition states, or intermediates are involved. Specifically, for the internal conversion process of $12^{\prime} \mathrm{CA}$ investigated in the current study, interactions between the cations and the "negative carbonyl end" of the probe appear to be crucial. In the case of $12^{\prime} \mathrm{CA}$ in ILs, the anions play a less prominent role. They likely compete together with the probe molecule for the cation binding positions or might perturb the electrostatic cation-probe interaction. For probes having their reactivity tied to a positively charged center, it is anticipated that electrostatic interactions with the anions might play a key role and the sensitivity to cations might be much weaker.

Acknowledgment. Financial support from the German Science Foundation and helpful discussions with J. Troe, V. G. Ushakov, and J. Schroeder are gratefully acknowledged. We thank the BASF AG, and here especially $\mathrm{H}$. Ernst, for providing the highly purified all-trans- $12^{\prime}$-apo- $\beta$-carotenoic- 12 '-acid sample and the ongoing support of our experiments. We are also thankful to M. Wagner (Solvent Innovation) and T. Beyersdorff (IoLiTec) for discussions on the properties of ionic liquids.

\section{References and Notes}

(1) Walden, P. Chem. Zentralbl. 1914, 1800.

(2) Wasserscheid, P.; Welton, T. Ionic Liquids in Synthesis, 2nd ed.; Wiley-VCH: Weinheim, 2007. 2101 .

(3) Endres, F.; El Abedin, S. Z. Phys. Chem. Chem. Phys. 2006, 8,

(4) Chiappe, C.; Pieraccini, D. J. Phys. Org. Chem. 2005, 18, 275.

(5) Tokuda, H.; Tsuzuki, S.; Susan, M. A. B. H.; Hayamizu, K.; Watanabe, M. J. Phys. Chem. B 2006, 110, 19593.

(6) Tokuda, H.; Hayamizu, K.; Ishii, K.; Susan, M. A. B. H.; Watanabe, M. J. Phys. Chem. B 2005, 109, 6103.

(7) Strehmel, V.; Laschewsky, A.; Stoesser, R.; Zehl, A.; Herrmann, W. J. Phys. Org. Chem. 2006, 19, 318.

(8) Stoesser, R.; Herrmann, W.; Zehl, A.; Laschewsky, A.; Strehmel, V. Z. Phys. Chem. 2006, 220, 1309.

(9) Hyun, B. R.; Dzyuba, S. V.; Bartsch, R. A.; Quitevis, E. L. J. Phys. Chem. A 2002, 106, 7579.

(10) Giraud, G.; Gordon, C. M.; Dunkin, I. R.; Wynne, K. J. Chem. Phys. 2003, 119, 464

(11) Cang, H.; Li, J.; Fayer, M. D. J. Chem. Phys. 2003, 119, 13017.

(12) Rajian, J. R.; Li, S.; Bartsch, R. A.; Quitevis, E. L. Chem. Phys. Lett. 2004, 393, 372.

(13) Shirota, H.; Funston, A. M.; Wishart, J. F.; Castner, E. W., Jr. J. Chem. Phys. 2005, 122, 184512.

(14) Xiao, D.; Rajian, J. R.; Cady, A.; Li, S.; Bartsch, R. A.; Quitevis,

E. L. J. Phys. Chem. B 2007, 111, 4669.

(15) Asaki, M. L. T.; Redondo, A.; Zawodzinski, T. A.; Taylor, A. J. J. Chem. Phys. 2002, 116, 10377

(16) Yamamoto, K.; Tani, M.; Hangyo, M. J. Phys. Chem. B 2007, 111, 4854.

(17) Triolo, A.; Russina, O.; Arrighi, V.; Juranyi, F.; Janssen, S.; Gordon, C. M. J. Chem. Phys. 2003, 119, 8549.

(18) Triolo, A.; Russina, O.; Hardacre, C.; Nieuwenhuyzen, M.; Gonzalez, M. A.; Grimm, H. J. Phys. Chem. B 2005, 109, 22061.

(19) Wishart, J. F.; Neta, P. J. Phys. Chem. B 2003, 107, 7261.

(20) Wishart, J. F.; Lall-Ramnarine, S. I.; Raju, R.; Scumpia, A.; Bellevue, S.; Ragbir, R.; Engel, R. Rad. Phys. Chem. 2005, 72, 99.

(21) Brands, H.; Chandrasekhar, N.; Unterreiner, A.-N. J. Phys. Chem. B 2007, 111, 4830 .

(22) Arzhantsev, S.; Hui, J.; Baker, G. A.; Maroncelli, M. J. Phys. Chem. B 2007, 111, 4978.

(23) Jin, H.; Baker, G. A.; Arzhantsev, S.; Dong, J.; Maroncelli, M. J. Phys. Chem. B 2007, 111, 7291 .

(24) Funston, A. M.; Fadeeva, T. A.; Wishart, J. F.; Castner, E. W., Jr. J. Phys. Chem. B 2007, 111, 4963.

(25) Paul, A.; Samanta, A. J. Phys. Chem. B 2007, 111, 4724

(26) Arzhantsev, S.; Jin, H.; Ito, N.; Maroncelli, M. Chem. Phys. Lett. 2006, $417,524$.

(27) Headley, L. S.; Mukherjee, P.; Anderson, J. L.; Ding, R.; Halder, M.; Armstrong, D. W.; Song, X.; Petrich, J. W. J. Phys. Chem. A 2006, 110,9549 .

(28) Samanta, A. J. Phys. Chem. B 2006, 110, 13704.

(29) Saha, S.; Mandal, P. K.; Samanta, A. Phys. Chem. Chem. Phys. 2004, 6, 3106.

(30) Ito, N.; Arzhantsev, S.; Heitz, M.; Maroncelli, M. J. Phys. Chem. B 2004, 108, 5771 .

(31) Ito, N.; Arzhantsev, S.; Maroncelli, M. Chem. Phys. Lett. 2004, $396,83$.

(32) Ingram, J. A.; Moog, R. S.; Ito, N.; Biswas, R.; Maroncelli, M. J. Phys. Chem. B 2003, 107, 5926.

(33) Arzhantsev, S.; Ito, N.; Heitz, M.; Maroncelli, M. Chem. Phys. Lett. 2003, 381, 278 . 
(34) Baker, S. N.; Baker, G. A.; Kane, M. A.; Bright, F. V. J. Phys. Chem. B 2001, 105, 9663.

(35) Wakai, C.; Oleinikova, A.; Ott, M.; Weingärtner, H. J. Phys. Chem. B 2005, 109, 17028 .

(36) Daguenet, C.; Dyson, P. J.; Krossing, I.; Oleinikova, A.; Slattery, J. M.; Wakai, C.; Weingärtner, H. J. Phys. Chem. B 2006, 110, 12682.

(37) Weingärtner, H. Z. Phys. Chem. 2006, 220, 1395.

(38) Krossing, I.; Slattery, J. M.; Daguenet, C.; Dyson, P. J.; Oleinikova, A.; Weingärtner, H. J. Am. Chem. Soc. 2006, 128, 13427.

(39) Weingärtner, H.; Sasisanker, P.; Daguenet, C.; Dyson, P. J.; Krossing, I.; Slattery, J. M.; Schubert, T. J. Phys. Chem. B 2007, 111, 4775 (40) Wulf, A.; Ludwig, R.; Sasisanker, P.; Weingärtner, H. Chem. Phys. Lett. 2007, 439, 323.

(41) Katritzky, A. R.; Fara, D. C.; Yang, H.; Tämm, K.; Tamm, T.; Karelson, M. Chem. Rev. 2004, 104, 175.

(42) Mellein, B. R.; Aki, S. N. V. K.; Ladewski, R. L.; Brennecke, J. F. J. Phys. Chem. B 2007, 111, 131 .

(43) Reichardt, C. Green Chem. 2005, 7, 339.

(44) Reichardt, C. Chem. Rev. 1994, 94, 2319. 591 .

(45) Carmichael, A. J.; Seddon, K. R. J. Phys. Org. Chem. 2000, 13,

(46) Fletcher, K. A.; Storey, I. A.; Hendricks, A. E.; Pandey, S.; Pandey, S. Green Chem. 2001, 3, 210.

(47) Aki, S. N. V. K.; Brennecke, J. F.; Samanta, A. Chem. Commun. 2001, 413.

(48) Köddermann, T.; Wertz, C.; Heintz, A.; Ludwig, R. Angew. Chem., Int. Ed. 2006, 45, 3697 .

(49) Wulf, A.; Köddermann, T.; Wertz, C.; Heintz, A.; Ludwig, R. Z. Phys. Chem. 2006, 220, 1361.

(50) Crowhurst, L.; Falcone, R.; Lancaster, N. L.; Llopis-Mestre, V.; Welton, T. J. Org. Chem. 2006, 71, 8847.

(51) Oehlke, A.; Hofmann, K.; Spange, S. New J. Chem. 2006, 30, 533.

(52) Stalke, S.; Wild, D. A.; Lenzer, T.; Kopczynski, M.; Lohse, P. W.;

Oum, K. Phys. Chem. Chem. Phys. 2008 [Online early access] DOI: 10.1039/B720037D

(53) Kopczynski, M.; Lenzer, T.; Oum, K.; Seehusen, J.; Seidel, M. T.; Ushakov, V. G. Phys. Chem. Chem. Phys. 2005, 7, 2793.

(54) Lenzer, T.; Oum, K.; Seehusen, J.; Seidel, M. T. J. Phys. Chem. A 2006, 110,3159 .

(55) Bürsing, R.; Lenzer, T.; Oum, K. Chem. Phys. 2007, 331, 403.

(56) Ionic Liquids Database (IL Thermo); IUPAC and NIST, 2006.

(57) Handbook of Chemistry and Physics, 85th ed.; CRC Press: Boca Raton, 2004.

(58) "Product list including physicochemical data," Solvent Innovation, 2005.

(59) Crosthwaite, J. M.; Muldoon, M. J.; Dixon, J. K.; Anderson, J. L.; Brennecke, J. F. J. Chem. Thermodyn. 2005, 37, 559.

(60) Poole, C. F. J. Chromatogr. A 2004, 1037, 49.

(61) Wohlfarth, C.; Wohlfarth, B. Landolt-Börnstein -Viscosity of Pure Organic Liquids and Binary Liquid Mixtures-Pure Organometallic and Organononmetallic Liquids, Binary Liquid Mixtures; Springer: Berlin, Heidelberg, 2001; Vol. IV/18A

(62) Huddleston, J. G.; Visser, A. E.; Reichert, W. M.; Willauer, H. D.; Broker, G. A.; Rogers, R. D. Green Chem. 2001, 3, 156.

(63) Kopczynski, M.; Ehlers, F.; Lenzer, T.; Oum, K. J. Phys. Chem. A 2007, 111, 5370.

(64) Ehlers, F.; Wild, D. A.; Lenzer, T.; Oum, K. J. Phys. Chem. A 2007, 111, 2257.
(65) Wild, D. A.; Winkler, K.; Stalke, S.; Oum, K.; Lenzer, T. Phys. Chem. Chem. Phys. 2006, 8, 2499.

(66) Chynwat, V.; Frank, H. A. Chem. Phys. 1995, 194, 237.

(67) Englman, R.; Jortner, J. Mol. Phys. 1970, 18, 145.

(68) Schrödle, S.; Annat, G.; MacFarlane, D. R.; Forsyth, M.; Buchner, R.; Hefter, G. Chem. Commun. 2006, 1748.

(69) Schrödle, S.; Annat, G.; MacFarlane, D. R.; Forsyth, M.; Buchner, R.; Hefter, G. Aust. J. Chem. 2007, 60, 6.

(70) Hunt, P. A.; Gould, I. R.; Kirchner, B. Aust. J. Chem. 2007, 60, 9.

(71) Schröder, C.; Rudas, T.; Steinhauser, O. J. Chem. Phys. 2006, 125, 244506

(72) Liu, Z.; Huang, S.; Wang, W. J. Phys. Chem. B 2004, 108, 12978.

(73) Amyes, T. L.; Diver, S. T.; Richard, J. P.; Rivas, F. M.; Toth, K J. Am. Chem. Soc. 2004, 126, 4366.

(74) Ballinger, P.; Long, F. A. J. Am. Chem. Soc. 1960, 82, 795.

(75) Tsuzuki, S.; Tokuda, H.; Mikami, M. Phys. Chem. Chem. Phys. 2007, 9, 4780

(76) Mente, S. R.; Maroncelli, M. J. Phys. Chem. B 1999, 103, 7704.

(77) Lopes, J. N. C.; Pádua, A. A. H. J. Phys. Chem. B 2004, 108, 16893.

(78) Markham, G. D.; Bock, C. W. Struct. Chem. 1996, 7, 281.

(79) Schröder, C.; Rudas, T.; Neumayr, G.; Gansterer, W.; Steinhauser, O. J. Chem. Phys. 2007, 127, 044505

(80) Schröder, C.; Wakai, C.; Weingärtner, H.; Steinhauser, O. J. Chem Phys. 2007, 126, 084511

(81) The order of magnitude of the apparent activation energy arising from the temperature-dependent increase of the thermally averaged IC rate constants $k_{\mathrm{IC}}(T)$ can be estimated for well-known systems. Here we take the nonradiative decay of azulene from its $S_{2}$ state as an example. Employing reasonable Whitten-Rabinovitch densities of states $\rho(E)$ for $S_{2}$ azulene (for calculating the thermal vibrational Boltzmann distribution) and the wellknown $k_{\mathrm{IC}}(E)$, as measured, e.g., in molecular beam studies (for details, see the recent compilation of data on the photophysics and intramolecular dynamics of azulene in Hold et al. J. Chem. Phys. 2003, 119, 11192), one indeed observes an Arrhenius-type behavior for $k_{\mathrm{IC}}(T)$ in the range 298$348 \mathrm{~K}$, and the extracted apparent activation energy is ca. $4 \mathrm{~kJ} \mathrm{~mol}^{-1}$, which is similar to the experimental $E_{\mathrm{a}}$ values found for the decay of the $\mathrm{S}_{1} / \mathrm{ICT}$ state of $12^{\prime} \mathrm{CA}$. We are therefore confident that the observed increase of the IC rate constant with temperature in ILs and organic solvents is mainly due to the intrinsic energy dependence of the nonradiative transition.

(82) Chen, Z.; Lee, C.; Lenzer, T.; Oum, K. J. Phys. Chem. A 2006 110,11291

(83) Huppert, D.; Ittah, V.; Kosower, E. M. Chem. Phys. Lett. 1989, $159,267$.

(84) Ittah, V.; Huppert, D. Chem. Phys. Lett. 1990, 173, 496.

(85) Chapman, C. F.; Maroncelli, M. J. Phys. Chem. 1991, 95, 9095.

(86) Argaman, R.; Huppert, D. J. Phys. Chem. B 2000, 104, 1338.

(87) Argaman, R.; Molotsky, T.; Huppert, D. J. Phys. Chem. A 2000 104, 7934

(88) Pocker, Y.; Spyridis, G. T. J. Am. Chem. Soc. 2002, 124, 10373

(89) Springer, G.; Elam, C.; Edwards, A.; Bowe, C.; Boyles, D.; Bartmess, J.; Chandler, M.; West, K.; Williams, J.; Green, J.; Pagni, R. M.; Kabalka, G. W. J. Org. Chem. 1999, 64, 2202.

(90) Pocker, Y.; Spyridis, G. T. J. Am. Chem. Soc. 2002, 124, 7390.

(91) Pocker, Y.; Ciula, J. C. J. Am. Chem. Soc. 1989, 111, 4728.

(92) Thompson, P. A.; Simon, J. D. J. Chem. Phys. 1992, 97, 4792.

(93) Barthel, J.; Deser, R. J. Sol. Chem. 1994, 23, 1133. 